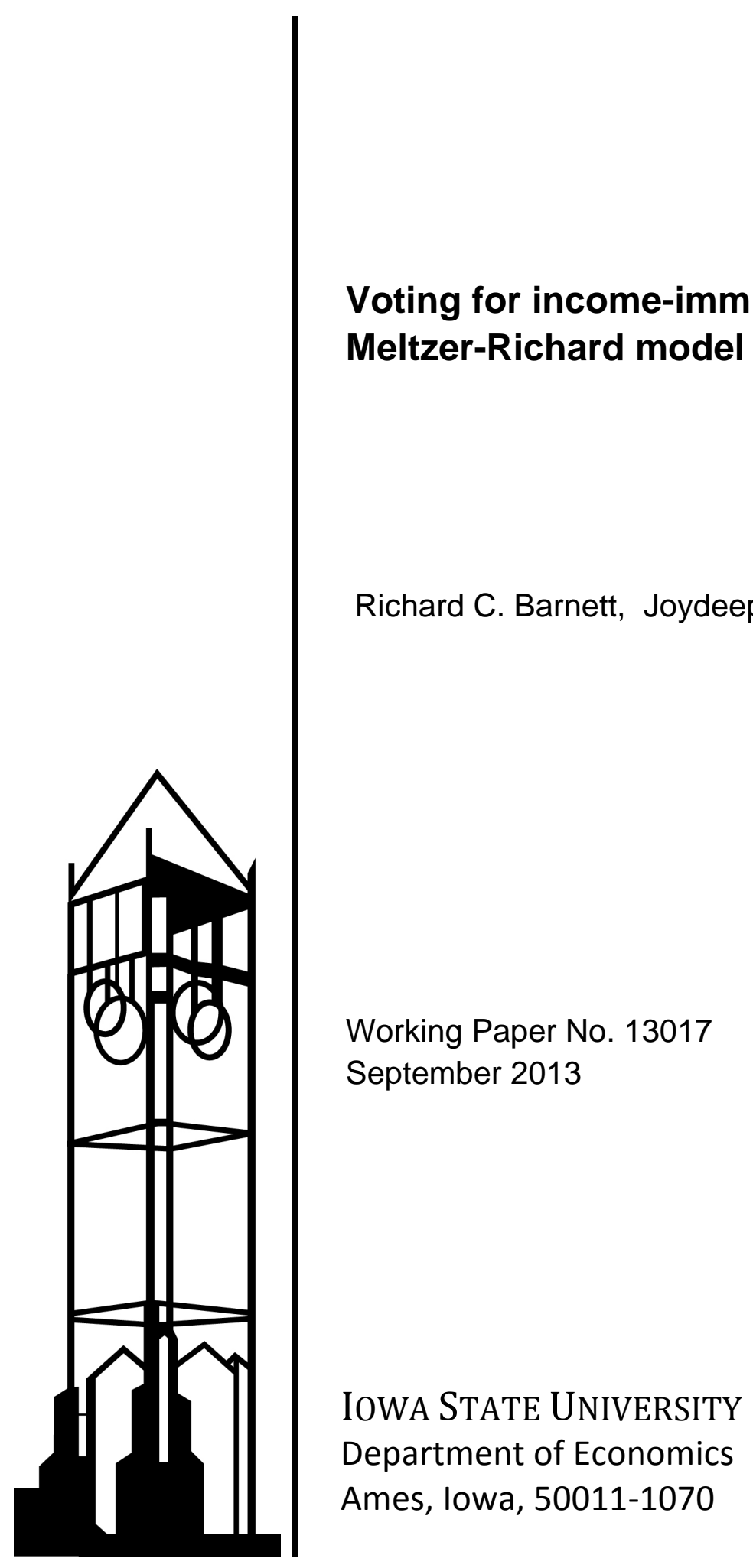

lowa State University does not discriminate on the basis of race, color, age, religion, national origin, sexual orientation, gender identity, genetic information, sex, marital status, disability, or status as a U.S. veteran. Inquiries can be directed to the Director of Equal Opportunity and Compliance, 3280 Beardshear Hall, (515) 294-7612. 


\title{
VOTING FOR INCOME-IMMISERIZING Redistribution In The Meltzer-Richard MODEL
}

\author{
Richard C. Barnett*, Joydeep Bhattacharya ${ }^{\dagger}$ Helle Bunzel ${ }^{\ddagger}$
}

July $17,2013^{\S}$

\begin{abstract}
This paper argues that income received via redistributive transfers, unlike labor income, requires no direct sacrifice of leisure; this makes it attractive to many voters even if it leaves them poorer. This point is made within the classic Meltzer and Richard (1981) model wherein heterogeneous voters evaluate an income-redistribution program that finances a lump-sum transfer to all via a distorting income tax. The politicalequilibrium policy under majority rule is the tax most preferred, utility-wise, by the median voter. She, and many poorer voters, may support income redistribution that, ironically, leaves them poorer in income terms but with higher utility. (JEL H2, E6, D $72)$
\end{abstract}

* Corresponding author: Associate Clinical Professor, Department of Economics, LeBow College of Business, Drexel University, Philadelphia PA 19104, USA. Tel.: 215-895-6972. E-mail: rcb63@drexel.edu

${ }^{\dagger}$ Professor, Department of Economics, Iowa State University, Ames IA 50011-1070, USA. Phone: (515) 294 5886; E-mail: joydeep@iastate.edu

${ }^{\ddagger}$ Associate Professor, Department of Economics, Iowa State University, Ames IA 50011-1070, USA. Phone: (515) 294 6163; E-mail: hbunzel@iastate.edu

${ }^{\S}$ We thank seminar and conference participants at Macquarie University, Queensland University of Technology, University of Oulu, and the Canadian Economic Association, two anonymous referees, James Ziliak (the co-editor), Monisankar Bishnu, Alan Meltzer, Min Wang, Marie-Louise Leroux, and Jean-Francois Wen for useful comments on earlier drafts of the paper. Special thanks to Torben Andersen for sharing his insights on the subject matter of this paper. 


\section{Introduction}

Political scientists have long pondered over the conflict between capitalistic and democratic principles. The former, as Iverson (2006) argues, "produces stark inequalities in the distribution of property and income, while the latter divides power in a manner that is in principle egalitarian (one person, one vote)." This power distribution has been characterized as rule of the poor, suggesting democracy is a regime that is most favorable to the many who are poor (the "99\%") unlike aristocracy and oligarchy which privilege the rich few. How so? Democracy gives people voting power to take other people's money and to redistribute wealth. The underlying logic is as follows: "if majority rule and universal suffrage were introduced into a society marked by massive inequality, then most voters, being relatively poor, would inevitably favor taxing the rich and transferring the proceeds downward." (Shapiro, 2002). To most political scientists, "it is nearly axiomatic that democracy serves as a mechanism for redistribution." (Gerring et. al. 2012) ${ }^{1}$ In this paper, we argue, even if this is true, i.e., the poor in a democracy do in fact vote to tax the rich and redistribute downward, they may not end up richer after all.

We make this point within the context of the Meltzer-Richard model (Meltzer and Richard, 1981), arguably the point of departure for the literature formalizing the size of government and the amount of redistribution that emerges in a democracy. Using one

\footnotetext{
${ }^{1}$ To Plato and Aristotle, to James Madison and John Adams, and to numerous conservative commentators thereafter, the inevitability of a "soak the rich" agenda of poor voters represents a major flaw in democracy. The Economist (2012) suggests John Adams "worried that rule by the masses would lead to heavy taxes on the rich in the name of equality. As a consequence, "the idle, the vicious, the intemperate would rush into the utmost extravagance of debauchery, sell and spend all their share, and then demand a new division of those who purchased from them."”
} 
simple variable - income inequality - the Meltzer-Richard model provides parsimonious predictions about citizens' preferences for income redistribution in democracies. It relies on a intuitively simple idea: since the median voter - the all-important voter in a democracy with universal suffrage and majority rule - tends to have below-average income (assuming a commonly-observed right-skewed distribution of pre tax income), she has a personal interest in supporting income redistribution. We ask, what is the exact basis for her support? Is it simply her desire to get richer?

The vast popularity of the Meltzer-Richard model, as noted, is due to its elegance and sharp prediction. ${ }^{2}$ In the model (or, in the slight reformulation presented in Persson and Tabellini, 2002a,b), voters differ in one fundamental dimension, their innate productivity or "effective time". Anticipating labor-leisure reactions, they vote on a pure, incomeredistributive program that pays the same lump-sum transfer to each voter financed by a distorting, linear, labor-income tax. Under direct democracy with universal suffrage and majority rule, the voter with median productivity is decisive; her preferences dictate what gets elected and implemented. If the median voter has lower-than-average productivity, a proportional tax on labor used to finance the lump-sum subsidy implies a net income transfer to this voter. The larger the gap between the median and mean productivities, the higher the tax rate, and hence, the larger the scale of redistributive income transfers (from rich to

\footnotetext{
${ }^{2}$ A Google search provides over 1800 citations for Meltzer and Richard (1981). Recent contributions address numerous issues impinging on (and impinged by) redistributive politics, including, among many others, tax avoidance (Traxler (2012)), social identity (Lindqvist and Östling (2013), Lupu and Pontusson (2011)), fairness (Alesina and Angeletos (2005)), distributional conflict (Acemoglu and Robinson (2006)), sociology (Kenworthy, 2007), and preference heterogeneity (Hodler (2008)). Other related studies emphasize the dynamic aspects of redistribution (see for example, Krusell and Rios-Rull (1999), Azzimonti et. al. $(2006,2008))$. Beramendi and Anderson (2008) contains useful discussion and summaries of this literature.
} 
poor voters) favored by the median voter. ${ }^{3}$ She is, however, constrained in the amount of redistribution she can direct her way - there are limits to how much the rich can be soaked - by the reduction in the size of the pie available for redistribution as tax rates increase.

The central idea that emerges from this framework is that democracies with the highest levels of inequality should see the greatest push for redistribution, because in such societies, the median voter stands to gain from taxes that redistribute income. ${ }^{4}$ But gain how? The literature appears silent on this question. Indeed, a casual reading of Meltzer and Richard (1981) and the subsequent literature evokes a nearly axiomatic sense the answer is income: what impels the impoverished median voter to support large-scale income redistribution has to be the prospect of receiving higher income post redistribution. In this paper, we demonstrate such a perception, seemingly true and obvious to us until we found otherwise, is not fully correct: in fact, counterexamples to this perception abound. For standard, C.E.S. preferences we derive simple conditions on the elasticity parameter for which the median voter elects a tax-transfer policy that leaves her poorer in income terms. And it's not just her. ${ }^{5}$

\footnotetext{
${ }^{3} \mathrm{~A}$ focus of much of the literature relates to empirical testing of a basic tenet of the Meltzer-Richard model: the size of government, as measured by the scale of publicly-funded income redistribution, is directly related to the level of income inequality in an economy (Meltzer and Richard (1983), Borge and Rattsø (2004), Pontusson and Rueda, (2010), and Georgiadis and Manning (2012), to name a few).

${ }^{4}$ Kenworthy and Pontusson (2005) find persuasive evidence favoring the Meltzer-Richard model showing "countries that have experienced greater increases in market inequality also exhibit larger increases in redistribution".

${ }^{5}$ The possibility that redistribution can impoverish the median voter (and others) in income terms seems to have been generally overlooked. An exception is Mulligan (2001). Using a variation of the Meltzer-Richard model which allows some tax proceeds to be used for non-redistributive purposes, he contends the median voter will be worse off with redistribution than they would be with no such program in place. This result, he points out,

"..has important implications for political-economic theories of redistribution, because it implies that the fully informed median voter cannot be expected to support programs of cash redistribution from rich to poor - such as the negative income tax - merely on the basis of his personal benefits from the program."
} 
Curiously, it is possible, despite receiving a positive net transfer, no agent emerges with more income post transfer than they would in the absence of democracy-induced redistribution.

At the heart of our result are two insights, the crowding-out of a person's labor income following an increase in transfer income, and the notion that no leisure is sacrificed when $\$ 1$ of labor income is replaced by $\$ 1$ of transfer income. If the crowding-out is severe enough, the intended beneficiaries of the income redistribution program may find themselves poorer but happier from the leisure gained from a (possibly incomplete) swap of labor income with transfer income. ${ }^{6}$

The overall implication is striking: the basis for income-redistributive policies in a democracy, ironically, may not be income. This is not to suggest that, in the Meltzer-Richard model, redistribution does not achieve its primary objective: evening out disparities in income. All it means is that democracy-induced redistribution may not lead most to receive more income than they would in its absence.

\section{The model}

\subsection{Preliminaries}

The model follows the classic Meltzer and Richard (1981) framework, or, more precisely, its slight reformulation found in Persson and Tabellini (2002, Chapt. 6). This is a singlegood, static economy with a continuum of agents - denoted by $i$ - who are distinguished by their endowment of "effective time", $e$, over and above the one unit of time available to

In our case, voters benefit from redistribution, though not necessarily by the way of greater income.

${ }^{6}$ The argument is fleshed out clearly in Section 2.2 below. 
all. Assume $e$ is distributed according to a distribution $\mathcal{G}$ with support $[\underline{\xi}, \bar{\xi}]$, mean $\bar{e}$, and median $e^{m}<\bar{e}$, i.e., $\mathcal{G}$ is right or positive-skewed. ${ }^{7} \mathcal{G}$ captures the fundamental inequality in this economy.

Agents work and consume, and vote on a general redistributive policy, one that levies a payroll tax on everyone and rebates the revenue, in a lump-sum manner, equally to all agents. Let $l^{i}$ denote agent $i$ 's labor supply and $x^{i}$ her leisure. Then, agent $i$ 's time constraint is given by $1+e^{i}=x^{i}+l^{i}$. Those with higher $e-$ sometimes referred to as "richer agents" - have more effective time to devote to work and play.

Let $W^{i}\left(c^{i}, x^{i}\right)$ denote the utility of agent $i$, where $c$ is consumption. Assume $W^{i}\left(c^{i}, x^{i}\right) \equiv$ $U\left(c^{i}\right)+V\left(x^{i}\right)$ where $U$ and $V$, the same for all $i$, are strictly increasing and strictly concave. The budget constraint facing agent $i$ is given by

$$
c^{i}=(1-\tau) l^{i}+f
$$

where $\tau \in[0,1]$ is a payroll tax, $f$ is the common lump-sum transfer, and the wage rate is assumed to be 1 . Notice in this setup, consumption and income are really the same thing. Furthermore, note $\tau$ is collected from only those who supply positive amounts of labor (and hence, earn positive amounts of labor income).

Agent $i$ chooses $l^{i} \in\left[0,1+e^{i}\right)$ to maximize $W^{i}$ subject to (1) and the time constraint, taking $f$ and $\tau$ as given. The first-order condition for an interior solution is given by

$$
(1-\tau) U_{c}\left((1-\tau) l\left(e^{i}, \tau, f\right)+f\right) \equiv V_{x}\left(1+e^{i}-l\left(e^{i}, \tau, f\right)\right) .
$$

It is easily checked that the second-order conditions to this problem are satisfied. Given $l\left(e^{i}, \tau, f\right)$, leisure is then defined by, $x\left(e^{i}, \tau, f\right) \equiv 1+e^{i}-l\left(e^{i}, \tau, f\right)$. It is straightforward to

\footnotetext{
${ }^{7}$ In the numerical example below, we allow for $e$ in $[0, \infty]$.
} 
verify $\frac{\partial l\left(e^{i}, \tau, f\right)}{\partial e^{i}}>0$ and $\frac{\partial l\left(e^{i}, \tau, f\right)}{\partial f}<0$, that is, richer agents supply more labor while higher transfers reduces labor supply for each agent. Also $\frac{\partial l\left(e^{i}, \tau, f\right)}{\partial \tau}<0$ holds if the substitution effect of a tax increase dominates (weakly) the income effect; consequently, the labor supply (leisure) for each individual under a redistributive policy will be lower (higher) than in its absence, or $l\left(e^{i}, \tau, f\right)<l\left(e^{i}, 0,0\right)$ and $x\left(e^{i}, \tau, f\right)>x\left(e^{i}, 0,0\right)$.

The tax base is given by $\mathcal{L} \equiv \int l(e, \tau, f) d \mathcal{G}(e)$ where $l(e, \tau, f) \geq 0$. The government budget constraint is given by $f=\tau \mathcal{L}$. It is easy to verify that $\frac{d \mathcal{L}}{d \tau}<0$ implying an increase in the tax rate always reduces the tax base. This is the economy-wide deadweight loss from taxation. And this is what constrains the amount of redistribution in the economy.

C.E.S preferences for $U(\cdot)$ and $V(\cdot)$ form the bases of our analysis below: ${ }^{8}$

$$
W(c, x)=\left\{\begin{array}{c}
\frac{c^{1-\sigma}}{1-\sigma}+\frac{x^{1-\sigma}}{1-\sigma}, \sigma>0, \sigma \neq 1 \\
\ln c+\ln x \text { if } \sigma=1
\end{array}\right.
$$

In Appendix A, we provide solutions for work $l\left(e^{i}, \tau, f\right)$ and leisure $x\left(e^{i}, \tau, f\right)$. Our solutions establish $l\left(e^{i}, \tau, f\right)$ (and $\left.x\left(e^{i}, \tau, f\right)\right)$ are linear in $e^{i}$ and in $f$, and increasing in $e^{i}$. Further, $l\left(e^{i}, \tau, f\right)>0$ if

$$
\left(1+e^{i}\right)>f(1-\tau)^{-\frac{1}{\sigma}}
$$

For these functional forms, $f$ is computed as a fixed point of

$$
f=\tau \int_{f(1-\tau)^{-\frac{1}{\sigma}}-1}^{\bar{\xi}} \frac{(1-\tau)^{\frac{1}{\sigma}}(1+e)-f}{\left[(1-\tau)+(1-\tau)^{\frac{1}{\sigma}}\right]} d \mathcal{G}(e) .
$$

Evidently, a closed form for the fixed point for $f$, while desirable, is not obtainable from (5). To get at a closed form, suppose (4) holds for all $i$ implying every agent's labor supply

\footnotetext{
${ }^{8}$ By Bergson's theorem (Katzner, 1970), these represent the entire class of additively-separable, homothetic preferences.
} 
is interior for given $\tau$ and $f$. In that case, and only then, the tax base (the average labor supply, $\mathcal{L}$ ) equals the labor supply of the average time-endowment agent, $\bar{l}$. Hence, assuming (4), (5) can be replaced by $f=\tau \bar{l}$, where $\bar{l} \equiv l(\bar{e}, \tau, f)=\frac{(1+\bar{e})-(1-\tau)^{-\frac{1}{\sigma}} f}{\left[1+(1-\tau)^{1-\frac{1}{\sigma}}\right]}$; from this, we obtain the closed form, $f=\left[\tau(1+\bar{e})(1-\tau)^{\frac{1}{\sigma}}\right] /\left[(1-\tau)^{\frac{1}{\sigma}}+1\right]$.

Based on this solution, (4) reduces to $\left(1+e^{i}\right) \geq \frac{\tau}{(1-\tau)^{\frac{1}{\sigma}}+1}(1+\bar{e})$. And, in particular, since $l^{i}$ (and $x^{i}$ ) are linear and increasing in $e^{i}$, setting $e^{i}=\underline{\xi}$ (the minimum of the support of $e$ ) allows us to define a range of "permissible" tax rates for which the labor supply of each agent is positive, based on the inequality

$$
(1+\underline{\xi}) \geq \frac{\tau}{(1-\tau)^{\frac{1}{\sigma}}+1}(1+\bar{e})
$$

From (6), it is easy to establish there exists a unique $\tau^{*} \equiv \tau^{*}(\sigma) \in(0,1)$ such that

$$
(1+\underline{\xi}) \gtreqless \frac{\tau}{(1-\tau)^{\frac{1}{\sigma}}+1}(1+\bar{e}) \text { for } \tau \gtreqless \tau^{*} .
$$

The set of permissible tax rates, the range for which all agents choose an interior labor supply is then $\left[0, \tau^{*}\right)$. In this range, the tax base (the average labor supply) equals the labor supply of the average time-endowment agent, and erstwhile derived closed-form expressions for $l, x$, and $f$ (presented in Appendix A) are valid.

\subsection{Diagrammatic intuition}

To facilitate a clear understanding of the underlying economic intuition for a given tax/transfer scheme, consider Figure 1a which captures a canonical configuration. ${ }^{9}$ In the figure, the

\footnotetext{
${ }^{9}$ As noted, the discussion here takes as given the tax-transfer policy which ultimately is determined in a voting process described below. Additionally, Figures 1a-d show the agent obtains higher utility post policy. Of course, this need not be the case, and certainly won't be for all agents in the post policy world.
} 
agent's budget line without redistribution (with slope -1) is shown as the segment $A A^{\prime}$. Faced with zero tax, the agent chooses point $W$ and consumes $O E$. With the tax-transfer program, the effective budget line, $B B^{\prime} A^{\prime}$, is flatter (with slope $-(1-\tau)$ ), and has a kink at $B^{\prime}$. (The budget line with (without) redistribution is in red (black)). Why? While we can envision the budget line $B B^{\prime}$ to extend to $B^{\prime \prime}$, any point on the segment $B^{\prime} B^{\prime \prime}$ is not attainable since the agent is constrained by the fact that even with the transfer she cannot enjoy more leisure than the entirety of her time endowment, $1+e^{i}$. (Note, the way Figure 1a is drawn, the point $B$ lies below point $A$ signifying that her potential maximum consumption/income is lower post policy. This may not always be the case, as shown in Figures 1b and 1d.)

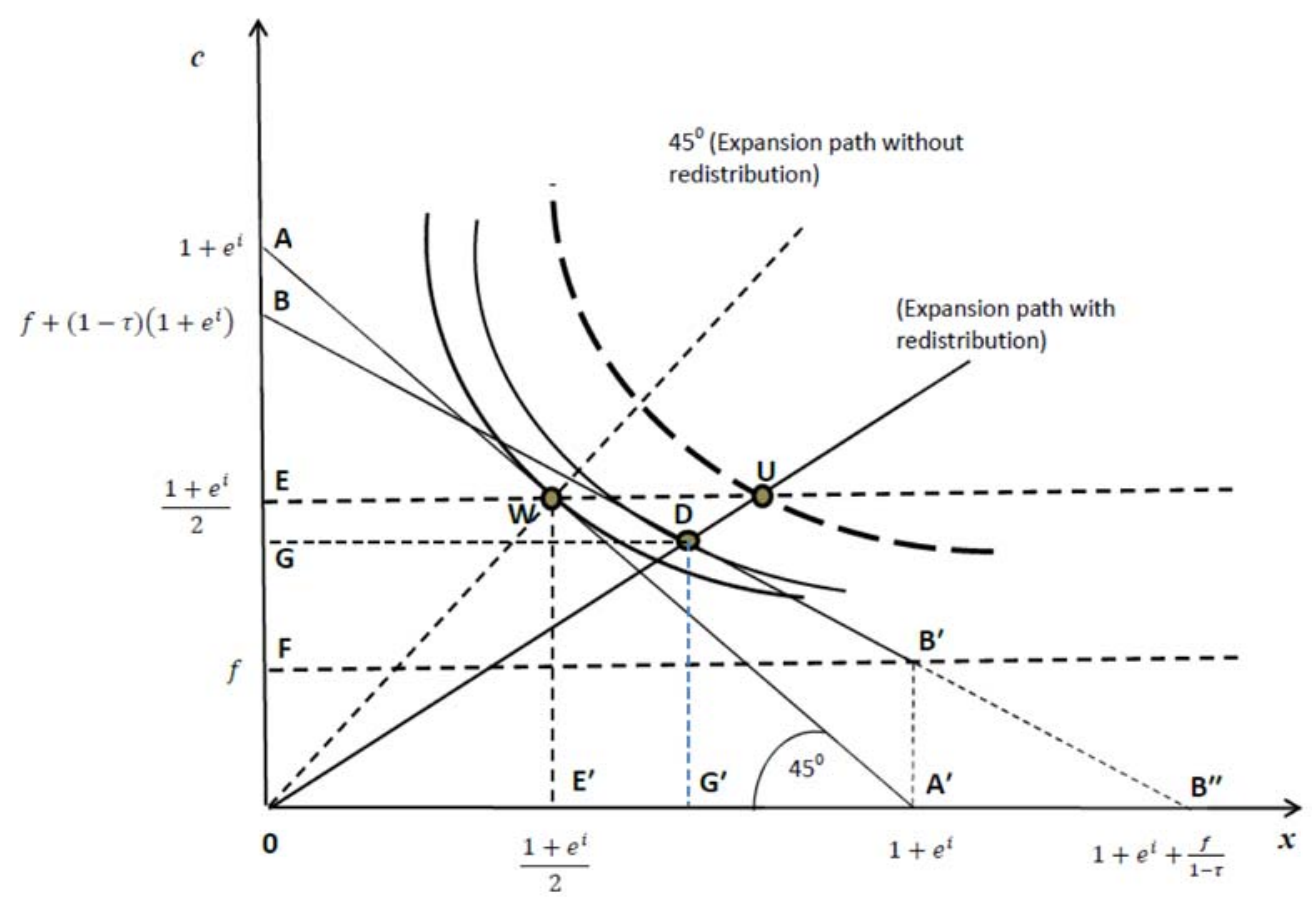

Figure 1a: $A$ lies above $B$; more leisure, less income post policy 
Faced with the tax and transfer, her optimal choice is at $D$ where she consumes $O G=$ $O F+F G$. Pre policy, she consumed $O E=O F+F G+G E$, all of which she financed by the sweat of her own labor. In the configuration of Figure 1a, post policy she consumes less: $O G$ $<O E$. Also, the income from her own labor supply has fallen from $O E$ to $G F(O G-O F)$ since the $O F$ part is funded via the transfer. $O F+G E$ is the labor income she eschews because of the policy. In effect then, the policy permits her to swap $O F+G E$ of incomefruits of her own labor - for $O F$ units of "labor-free" transfer income and $E^{\prime} G^{\prime}$ additional units of leisure. Two points are worthy of note here. First, even a one-for-one swap of own labor income with transfer income, were it possible, would not be utility-neutral; such a swap would raise utility because it increases leisure. ${ }^{10}$ Second, the agent may be willing to accept a less than one-for-one swap ( $O G$ for $O E)$ only because the transfer income helps her economize on her own labor, placing $D$ on a higher indifference curve than is $W$. It is this insight - explored further in Section 3.2 - that is key to understanding the results to follow.

What other sort of post-tax outcomes may emerge from our setup? Figure 1b illustrates a possibility similar to that of Figure 1a but where point $B$ lies above point $A$ signifying that her potential maximum consumption/income is higher post policy, yet surprisingly, she emerges with less income post policy. In this case, her pre policy budget line lies everywhere inside the post policy budget line. Figures $1 \mathrm{c}$ and d illustrate the more conventional settings in which the agent ends up with higher income post policy.

\footnotetext{
${ }^{10}$ Unless the transfer is large enough, she cannot reach $U$, at which point, the swap of own labor income with transfer income is exactly one-to-one. As we will see below, the size of the transfer is contingent on the level of inequality in the economy.
} 


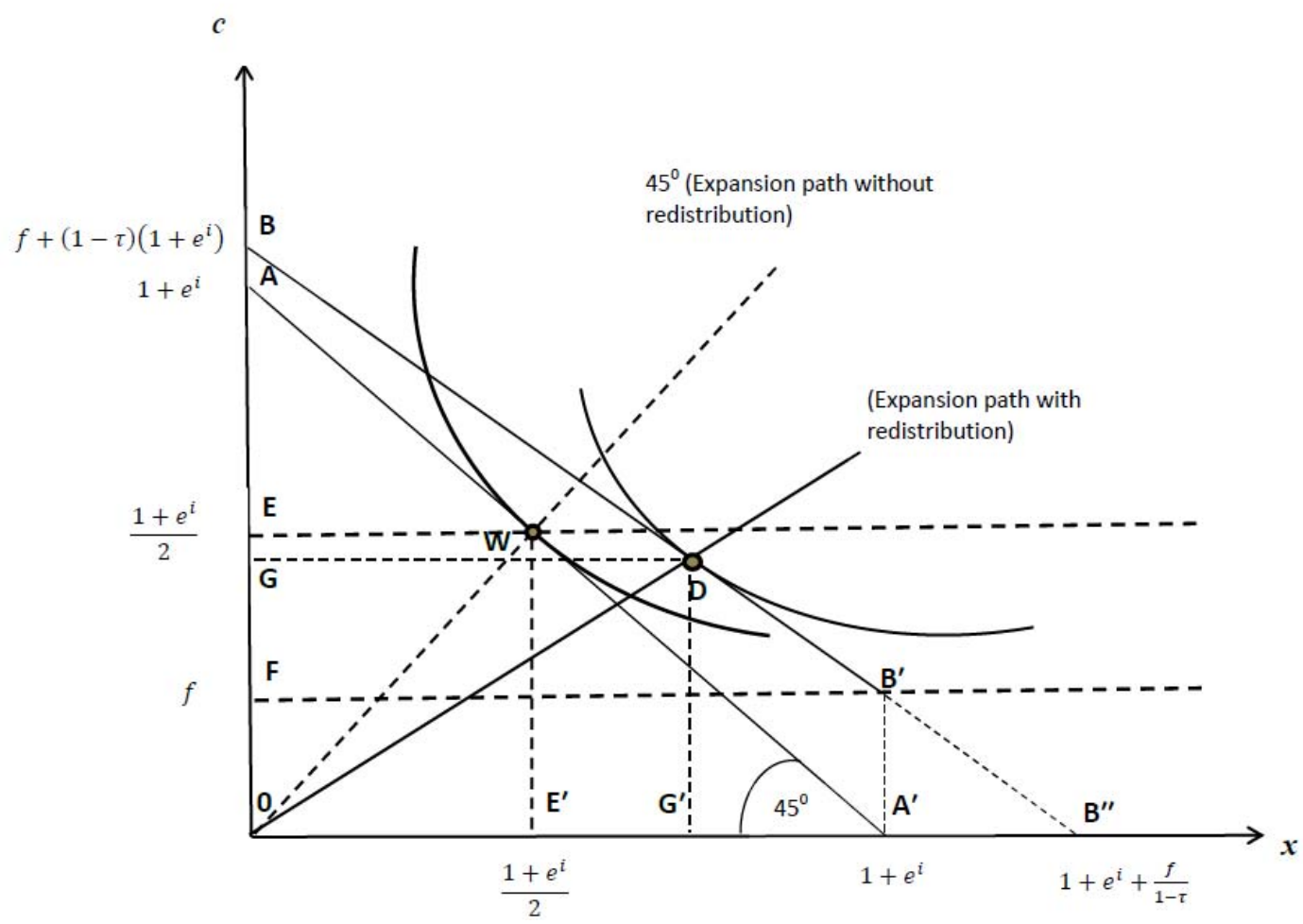

Figure 1b: $B$ lies above $A$

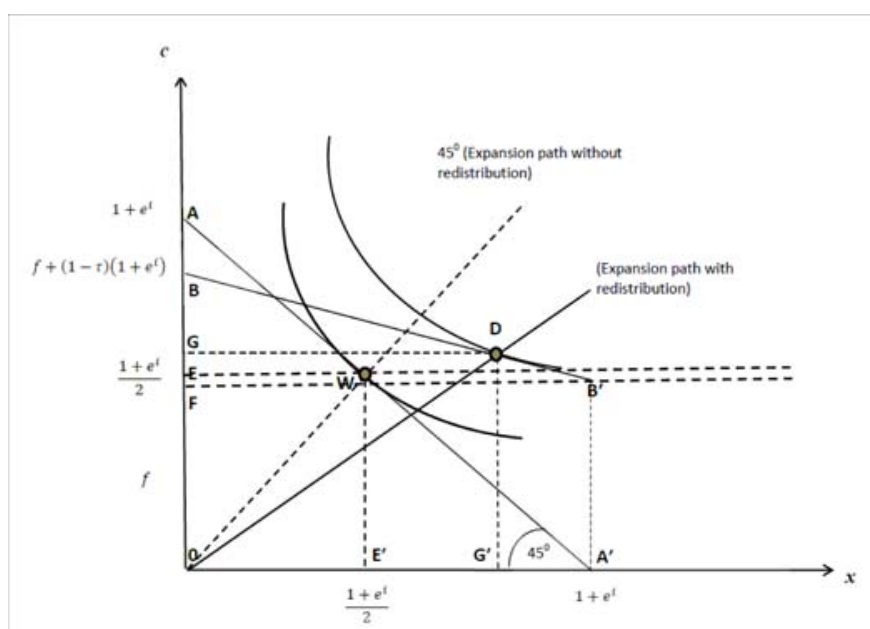

Figure 1c: $A$ above B; more income post policy

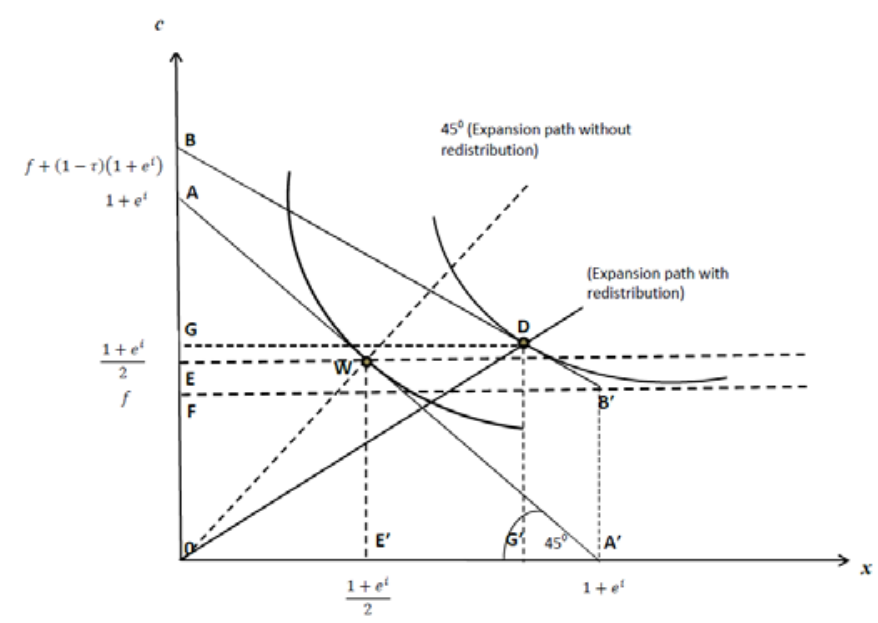

Figure 1d: $A$ below B; more income post policy

\subsection{Voting over redistributive policies}

The redistributive policy is voted upon by every agent. As is standard in the median-voter model, assume candidates care only about prevailing in the election and choose electoral 
platforms to achieve this purpose. They also precommit to implementing the elected redistribution policy if they win. Agent $i$ is assumed to vote for that candidate whose electoral platform $\tau$ is closest to her own most-preferred, denoted $\tau^{i}$. As in Meltzer and Richard, agents understand the tax rate affects the tax base, $\mathcal{L}$, and the transfer $f$; they take these into consideration when computing $\tau^{i}$.

In general, the indirect utility of agent $i$ is given by

$$
W^{i}(\tau) \equiv U\left((1-\tau) l\left(e^{i}, \tau, f\right)+f\right)+V\left(1+e^{i}-l\left(e^{i}, \tau, f\right)\right)
$$

where $f=\tau \int l(e, \tau, f) d \mathcal{G}(e)$. Agent $i$ 's most-preferred tax rate is given by $\partial W^{i}(\tau) / \partial \tau=0$. Using the envelope theorem, it is easily checked that $\frac{\partial W^{i}(\tau)}{\partial \tau}=U_{c}().\left[\frac{d f}{d \tau}-l\left(e^{i}, \tau, f\right)\right]$ implying agent $i$ 's most-preferred tax rate, $\tau^{i}$, when interior, solves $\frac{d f}{d \tau}=l\left(e^{i}, \tau, f\right)$. [As an aside, note this implies $\frac{d f}{d \tau}>0$ or that the economy is on the upward-sloping portion of the tax-revenue Laffer curve]. When every agent's labor supply is interior, $\tau^{i}$ is implicitly determined from

$$
\tau^{i}=\frac{l\left(e^{i}, \tau^{i}, f^{i}\right)-\int l\left(e, \tau^{i}, f^{i}\right) d \mathcal{G}(e)}{\int l_{2}\left(e, \tau^{i}, f^{i}\right) d \mathcal{G}(e)+l\left(e^{i}, \tau^{i}, f^{i}\right) \int l_{3}\left(e, \tau^{i}, f^{i}\right) d \mathcal{G}(e)},
$$

where $f^{i}=\tau^{i} \int l\left(e, \tau^{i}, f^{i}\right) d \mathcal{G}(e)$ is the transfer evaluated at $\tau^{i}$, and $l_{j}($.$) refers to the partial$ derivative of $l($.$) with respect to its j$ th argument.

The numerator of (9) can be rewritten as $\frac{1}{\tau^{i}}\left(\tau^{i} l\left(e^{i}, \tau^{i}, f^{i}\right)-f^{i}\right)$; since the denominator of (9) is negative, an agent only votes for a positive tax rate if the transfer net of labor income, $f^{i}-\tau^{i} l\left(e^{i}, \tau^{i}, f^{i}\right)$, is positive. Agents with $l\left(e^{i}, \tau^{i}, f^{i}\right) \geq \mathcal{L}$ are constrained to vote for a zero tax. When preferences for leisure and consumption are homothetic (as in (3)) and each agent's labor supply is positive, average labor supply $(\mathcal{L})$ coincides with the labor 
supply of the agent with average time endowment, $l\left(\bar{e}, \tau^{i}, f^{i}\right)$. Then, (9) can be rewritten as

$$
\tau^{i}=\frac{l\left(e^{i}, \tau^{i}, f^{i}\right)-l\left(\bar{e}, \tau^{i}, f^{i}\right)}{\int l_{2}\left(e, \tau^{i}, f^{i}\right) d \mathcal{G}(e)+l\left(e^{i}, \tau^{i}, f^{i}\right) \int l_{3}\left(e, \tau^{i}, f\right) d \mathcal{G}(e)}
$$

It follows, the average time-endowment agent (and those richer) vote for a zero tax, and the median effective-time agent votes for a positive tax.

Following Meltzer and Richard (1981), if $\tau^{i}$ is monotonically declining in $e^{i}$, the median voter theorem identifies the Condorcet winner (a.k.a., the elected tax rate or the equilibrium tax rate) as the tax rate most preferred by the agent with the median time endowment (i.e., the $\tau$ most favored by the agent with $e=e^{m}$, henceforth $\left.\tau^{m}\right)$. Replacing $e^{i}$ with $e^{m}$ in (11) yields the implicit expression for $\tau^{m}$.

Using (3) and (10), the most-preferred tax of agent $i$ satisfies

$$
\tau^{i}\left(1-\tau^{i}\right)^{\frac{1}{\sigma}}+\tau^{i}\left(1-\tau^{i}\right)=\sigma\left(1-\frac{\left(1+e^{i}\right)}{(1+\bar{e})}\right)\left(1-\tau^{i}\right)\left(1+\left(1-\tau^{i}\right)^{\frac{1}{\sigma}}\right)^{2}
$$

A derivation of (11) is contained in Appendix B. Replacing $e^{i}$ with $e^{m}$ in (11) yields the implicit expression for the equilibrium tax rate, $\tau^{m}$. It bears emphasis here that (11) yields closed-form solutions only for selected integer values of $\sigma$.

Our expression (11) presupposes $l\left(e^{i}, \tau\right)>0$ for all $i$, and hence, is only valid if the fixed point of (11), evaluated at $e^{i}=e^{m}$, lies in the interval $\left[0, \tau^{*}\right)$. It turns out a condition similar to (6) ensures this is true.

\section{Lemma 1 If}

$$
(1+\underline{\xi}) \geq \frac{\sigma}{(1+\sigma)}(1+\bar{e})
$$

holds, then the elected tax, $\tau^{m}$, derived from (11), lies in the range of permissible tax rates, i.e., it satisfies $0<\tau^{m}<\tau^{*}$ where $\tau^{*}$ is defined in ( 7$)$. 
The proof is in Appendix C. Of course, (12) is a condition sufficient to ensure $\tau^{m}<\tau^{*}$; the elected tax rate may still satisfy this inequality even if (12) is violated. ${ }^{11}{ }^{12}$ Heuristically, the size of the transfer depends critically on $\bar{e}$ (the mean endowment). If this transfer is large relative to the time endowment of the lowest-endowed agent, that agent will choose not to work. Condition (12) puts a limit on how large the transfer can be and yet leave every agent with interior labor supply. Only then will $\tau^{m}$ be consistent with the tax choice of the median voter.

Summarizing, if (12) holds, the elected tax rate lies in the permissible range $\left[0, \tau^{*}\right)$ for which every agent chooses interior levels of labor supply. This means, if (12) holds, then at the elected tax rate, the average labor supply equals the labor supply of the average time-endowment agent; additionally, the closed-form expressions for $l, x$, and $f$ derived in the appendix are valid, and all such variables are interior at the elected tax rate.

\subsection{Discussion}

It bears emphasis the median voter's choice of the tax rate is one that maximizes her utility. What does such a tax rate imply about her income? Below, we establish that the median voter chooses a tax rate that does not maximize her income.

\footnotetext{
${ }^{11}$ This point is illustrated in our numerical example below. PDF given by $\alpha(\underline{\xi})^{\alpha}(\bar{\xi})^{-\alpha-1} /\left(1-(\underline{\xi} / \bar{\xi})^{\alpha}\right)$. Then (12) becomes

$$
(1+\underline{\xi}) \geq \frac{\sigma}{(1+\sigma)}\left(1+\frac{(\underline{\xi})^{\alpha}}{1-\left(\frac{\xi}{\bar{\xi}}\right)^{\alpha}}\left(\frac{\alpha}{\alpha-1}\right)\left(\frac{1}{(\underline{\xi})^{\alpha-1}}-\frac{1}{(\underline{\xi})^{\alpha-1}}\right)\right),
$$
}

${ }^{12} \mathrm{~A}$ condition such as (12) may easily be rewritten in terms of the parameters of the underlying distribution. For example, suppose $e$ is distributed according to a bounded Pareto distribution over support $[\xi, \bar{\xi}]$ with

written solely in terms of the underlying distributional parameters. 


\section{Proposition 1}

$$
\left.\frac{\partial y^{m}}{\partial \tau}\right|_{\tau^{m}}<0
$$

Locally near $\tau^{m}$, her income is declining in the tax rate; the implication is $\tau^{m}$ does not maximize her income. ${ }^{13}$ Intuitively, it is clear this derivative can never be positive since that would imply she could raise her consumption and leisure by choosing a higher tax.

At some level, this is somewhat to be expected; after all, anything that maximizes utility may not maximize one of its components. Nevertheless, three points deserve mention here. First, note Proposition 1 does not address what happens to median income globally, away from $\tau^{m}$. Second, the result has nothing to offer on the comparison between median voter's income pre and post policy. And third, perhaps most importantly, while the proposition argues the median voter does not maximize her income, it does not offer any insight into why she may choose a tax rate which leaves her with less income post policy.

Whether a voter's income post redistribution is less than her income pre redistribution depends on the global properties of her post redistribution income, $y^{i}=(1-\tau) l\left(e^{i}, \tau^{m}, f\right)+$ $f=l\left(e^{i}, \tau^{m}, f\right)-\tau\left[l\left(e^{i}, \tau^{m}, f\right)-l\left(\bar{e}, \tau^{m}, f\right)\right]$ versus $y^{i}=l\left(e^{i}, 0,0\right)$. It is easily seen

$$
\left.\frac{d y^{i}}{d \tau}\right|_{\tau=0}=\underbrace{\left[\frac{\partial l\left(e^{i}, \tau, f\right)}{\partial \tau}+\frac{\partial l\left(e^{i}, \tau, f\right)}{\partial f} \frac{d f}{d \tau}\right]_{\tau=0}}_{<0}-\left(l\left(e^{i}, 0,0\right)-l(\bar{e}, 0,0)\right)
$$

The first term (the underscored term) is negative, and captures the deadweight loss of distortionary taxation. The second term is the change in the net transfer brought on by the marginal change in the tax. If the median and mean endowment were to coincide, $\tau^{m}=0$; in

\footnotetext{
${ }^{13}$ We thank an anonymous referee and Torben M. Andersen for alerting us to this result. The proof follows straightforwardly from the first order conditions to the agent's problem, and from noting that $\tau^{m}$ satisfies $\frac{d f}{d \tau}-l\left(e^{m}, \tau, f\right)=0$.
} 
that case, $\left.\frac{d y^{m}}{d \tau}\right|_{\tau=\tau^{m}=0}<0$ for $e^{m}=\bar{e}$, and any marginal change in the tax always hurts the median voter. At the other end of the spectrum though, those with $e$ far less than $\bar{e}$ will see a marginal increase in their net transfer which may exceed the deadweight loss. Such agents may benefit income-wise. Outside of these limiting cases, the issue of whether redistribution raises or lowers overall income, is quite up in the air. This constitutes the analytical leverage of this study, and this is what we turn to next.

\section{Post-redistribution income and inequality}

The income of agent $i$ in the absence of policy is denoted by $y_{0}^{i} \equiv l\left(e^{i}, 0,0\right)$. For an arbitrary $\tau \in\left[0, \tau^{*}\right)$, the post tax-transfer income of agent $i$ is given by $y_{\tau}^{i} \equiv(1-\tau) l\left(e^{i}, \tau, f\right)+f$, where $f=\tau \bar{l}$. Define $D^{i}(\tau) \equiv y_{0}^{i}-y_{\tau}^{i}$, as the income gap, pre and post redistribution. If $D^{i}(\tau)>0$, agent $i$ is worse off in income terms post tax/transfer. Clearly, $D^{i}(0)=0$. Under (3), for $\tau \in\left[0, \tau^{*}\right)$, we can compute

$$
D^{i}(\tau)=\frac{1+e^{i}}{2}-\left[\frac{\tau(1+\bar{e})(1-\tau)^{\frac{1}{\sigma}}}{\left(1+(1-\tau)^{\frac{1}{\sigma}}\right)}+\frac{(1-\tau)^{1+\frac{1}{\sigma}}\left(\left(1+e^{i}\right)\left(1+(1-\tau)^{\frac{1}{\sigma}}\right)-\tau(1+\bar{e})\right)}{\left(1+(1-\tau)^{\frac{1}{\sigma}}\right)\left((1-\tau)+(1-\tau)^{\frac{1}{\sigma}}\right)}\right] .
$$

Of primary concern, however, is $D^{i}(\tau)$ evaluated at the elected tax rate, $\tau^{m}$. In other words, can $y_{\tau^{m}}^{i}<y_{0}^{i}$ or $D^{i}\left(\tau^{m}\right)>0$ for some $i$ ? for all $i$ ? ${ }^{14}$ As noted above, a closed-form

\footnotetext{
${ }^{14}$ Condition (13) may be rewritten in terms of the parameters of the underlying distribution. To see this, rewrite (13) as$$
D^{i}\left(\tau^{m}\right)>0 \Leftrightarrow\left(1+e^{i}\right)>\frac{\tau^{m}(1+\bar{e})\left(1-\tau^{m}\right)^{\frac{1}{\sigma}}\left(\frac{\left(1-\tau^{m}\right)^{\frac{1}{\sigma}}}{\left(1+\left(1-\tau^{m}\right)^{\frac{1}{\sigma}}\right)\left(\left(1-\tau^{m}\right)+\left(1-\tau^{m}\right)^{\frac{1}{\sigma}}\right)}\right)}{\left(\frac{1}{2}-\frac{\left(1-\tau^{m}\right)^{1+\frac{1}{\sigma}}}{\left(1-\tau^{m}\right)+\left(1-\tau^{m}\right)^{\frac{1}{\sigma}}}\right)} .
$$

Obviously, for given $\sigma, \tau^{m}$ depends on $e^{m}$ and $\bar{e}$ which, in turn, are purely functions of underlying distrib-
} 
solution for $\tau^{m}$ is available only for a few integer values for $\sigma$. So, a direct verification of $D^{i}\left(\tau=\tau^{m}\right)>0$ for a generic $\sigma$ is not possible. As such, we adopt the strategy of establishing $D^{i}(\tau) \geq 0$ (for all permissible $\tau$, which, of course includes $\tau^{m}$ ) but for a specific range of $\sigma \cdot{ }^{15}$

\subsection{Poorer income-wise}

Since we cannot, at this level of generality, establish the shape of $D^{i}(\tau)$, we present various illustrative configurations in Figure 2a-c. A road map of our strategy which makes use of these figures is provided below.

Assuming each agent's labor supply is interior (which it will be, whenever (12) holds), we write down a sufficient condition in Lemma 2 which ensures $\frac{\partial D^{i}}{\partial \tau}(\tau=0)>0$, thereby ruling out the possibility illustrated in Figure 2a. Note if $\tau^{m}=\tau_{B}^{m}$ it is still possible $D^{i}\left(\tau^{m}\right)>0$ in Figure 2a, but since we are unable to rule out $\tau^{m}=\tau_{A}^{m}$, we must preclude this path for $D^{i}(\tau)$

There still remains the possibility that $D_{\tau}^{i}(0)>0$, but $D^{i}(\tau)$ eventually decreases and becomes negative. Further, it could be that $D^{i}\left(\tau^{m}\right)>0$ (as shown now at $\tau^{m}=\tau_{A}^{m}$ ), but of course we cannot rule out $D^{i}\left(\tau^{m}\right)<0$ (as would be the case at $\tau^{m}=\tau_{B}^{m}$ ). See Figure utional parameters. As such, all terms on the right hand side of the above expression are, in principle, all functions of underlying distributional parameters.

${ }^{15}$ More generally though, if we could show $\mathcal{D}^{i}(\tau)>0$ for the admissible range of $\tau$ and for all $\sigma$, we'd have shown that, irrespective of the tax elected, each $i$ will be worse off post-redistribution. But this is not possible for all values of $\sigma$; after all,

$$
\lim _{\sigma \rightarrow \infty} \mathcal{D}^{i}(\tau)=\frac{1}{2} \frac{\tau}{\tau-2}\left(\bar{e}-e^{i}\right)<0 \quad \forall e^{i}<\bar{e} .
$$

This means, if $\sigma$ is sufficiently high, the income gap is negative at any arbitrary tax rate, implying, for high enough $\sigma$, everyone with $e^{i}<\bar{e}$ is better off with redistribution. In other words, immiserizing redistribution is unlikely to be a feature of high- $\sigma$ economies. 
$2 \mathrm{~b}$. There is no simple way to preclude this configuration for general $\sigma$. As such, we proceed to establish $D^{i}(\tau)>0$ for a specific $\sigma, \sigma=3$. This is done in Proposition 2. Once this is established, we proceed to show $\partial D^{i}(\tau) / \partial \sigma<0$ for all $\tau$ in the relevant range. Lemma 3 shows this and hence serves to expand the range of $\sigma$ for which $D^{i}(\tau)>0$ holds (as illustrated in Figure 2c).

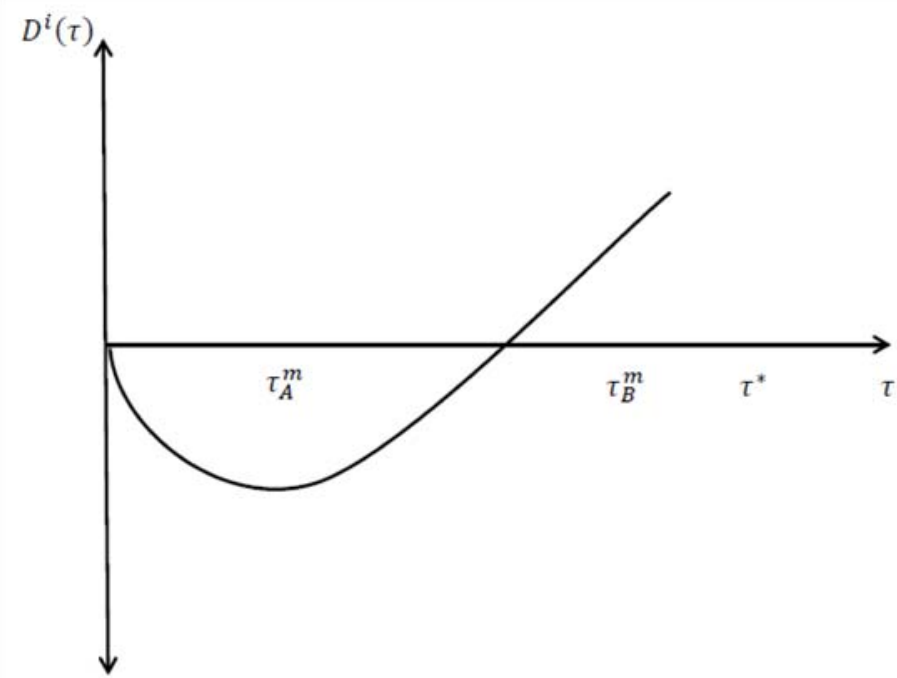

Figure 2a: A configuration of $D^{i}(\tau)$

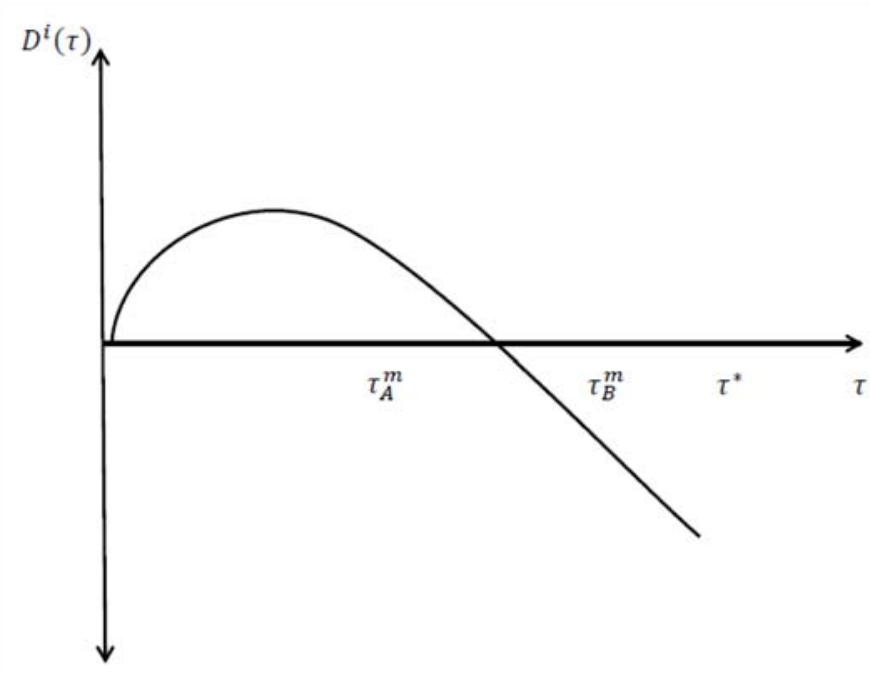

Figure 2b: A configuration of $D^{i}(\tau)$

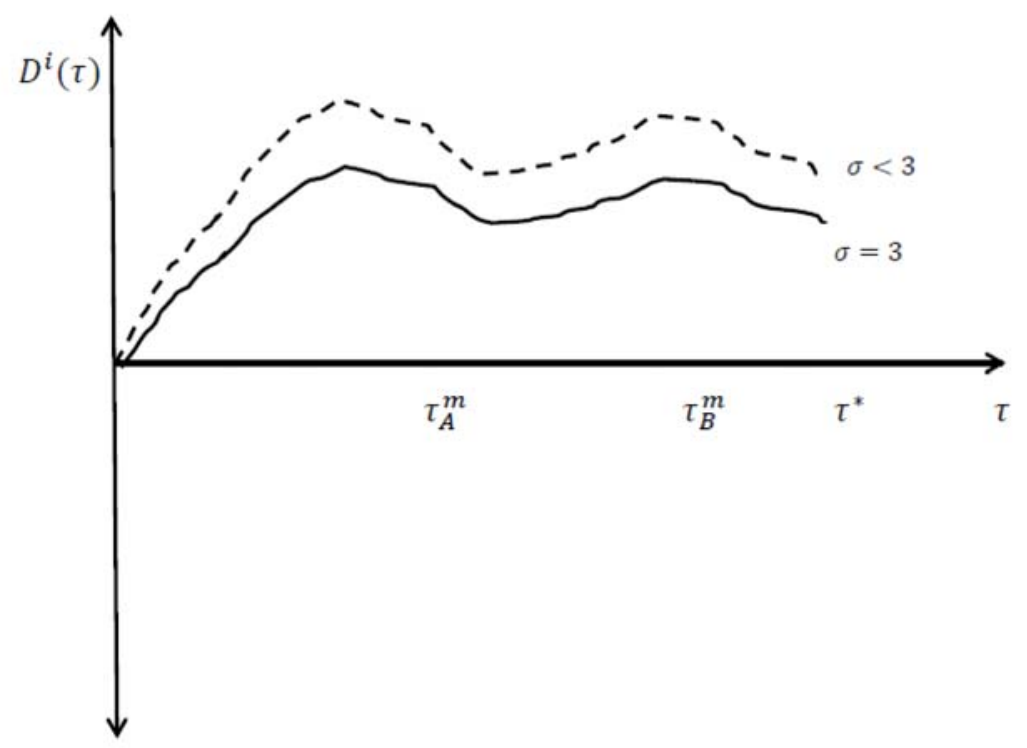

Figure 2c: A configuration of $D^{i}(\tau)$ 
Lemma 2 (i) $D^{i}(\tau)$ is a continuously differentiable function of both $\tau$ and $\sigma$.

(ii) $D^{i}(\tau)>0$ locally around $\tau=0$ if

$$
1+e^{i}>\frac{\sigma}{(1+\sigma)}(1+\bar{e})
$$

Note the similarity between (14) and (12). In particular, if (12) holds so does (14), but since (12) is not necessary for interior labor supply throughout, we assume the weaker (14) here. This condition is sufficient to ensure agent $i$ will not cease to work after the tax is imposed but is necessary to ensure $D_{\tau}^{i}(0)>0$. We are now ready to verify $D^{i}(\tau)>0$ holds for $\tau \in\left[0, \tau^{*}\right)$ for a specific value of $\sigma$.

Proposition 2 Suppose $\sigma=3$ and (14) holds for $\sigma=3$. Then, $D^{i}(\tau)>0$ for all $\tau \in\left[0, \tau^{*}\right)$.

The proof is in Appendix D.

Lemma $3 D^{i}(\tau)$ is decreasing in $\sigma$ for any $\tau \in(0,1)$.

It follows from Property (i) of Lemma 2, Proposition 2 and Lemma 3 that for $e^{i}$ satisfying (14), $D^{i}(\tau)>0, \forall 0<\sigma \leq 3$ and $\tau \in\left[0, \tau^{*}\right) \cdot{ }^{16}$ The thrust of Proposition (2) is established in the two corollaries below, our flagship results.

Corollary 1 Suppose $e^{m}$ satisfies (14) and $\tau^{m}<\tau^{*}$ holds. Then, $D^{m}\left(\tau^{m}\right)>0, \forall 0<\sigma \leq 3$. That is, for $\sigma$ in the range $(0,3]$, the income the median voter receives with redistribution is lower than what she receives in the absence of redistribution. ${ }^{17}$

\footnotetext{
${ }^{16}$ When $\sigma=3, \mathcal{D}^{i}(\tau)$ is a relatively-simple polynomial and it is easy to show the result. The fact it holds for $\sigma=3$ and by the proposition, for any $0<\sigma<3$, we have covered a large swath of the values of $\sigma$ that are consistent with empirical estimates of this parameter. Of course, it is possible $\mathcal{D}^{i}(\tau)>0$ holds for $\tau \in\left[0, \tau^{*}\right)$ for values of $\sigma>3$. The numerical examples below - see Appendix $\mathrm{F}$ - testify to this possibility.

${ }^{17}$ Note that if conditon (12) holds, we are assured (14) and $\tau^{m}<\tau^{*}$ holds. However, since (12) is sufficient but not necessary and may be unduly restrictive, we do not impose it.
} 
The irony in Corollary 1 is self evident. The median voter, in spite of being the decisive voter, chooses to immiserize herself in income terms. If it is not the prospect of receiving higher net income, what encourages the median voter to support such income redistribution? The answer, almost by default, has to be leisure. ${ }^{18}$ Specifically, she raises her utility through greater leisure by replacing labor income with labor-free transfer income. Ultimately, this increase in her utility is bankrolled on net by those at the higher end of the distribution who suffer utility declines as a result. The numerical example below will lay bare these trade-offs.

Is the fate of the median voter shared by others?

Corollary 2 Suppose $\underline{\xi}$ satisfies (12). Then, $D^{i}\left(\tau^{m}\right)>0, \forall 0<\sigma \leq 3$. That is, for $\sigma$ in the range $(0,3]$, the post tax-transfer income of every voter is lower.

Of course, it bears emphasis here that the preconditions outlined in these corollaries are merely sufficient..$^{19}$

\section{$3.2 \quad$ Numerics}

Next, we present an example that a) illustrates the applicability of our results to a much wider portion of the parameter space, and b) brings our analysis in some contact with the data. ${ }^{20}$ To that end, assume preferences are as in (3). Let $e$ be distributed according to a

\footnotetext{
${ }^{18}$ To see this, denote the leisure of agent $i$ in the absence of policy by $x_{0}^{i} \equiv x\left(e^{i}, 0,0\right)$. The post tax-transfer leisure of agent $i$ under the elected tax policy is denoted by $x_{\tau^{m}}^{i} \equiv x\left(e^{i}, \tau^{m}, f^{m}\right)$. Since (18) establishes labor supply is declining in the tax rate, and since the elected tax rate is positive, $x_{\tau^{m}}^{i}>x_{0}^{i}$ must obtain.

${ }^{19}$ Corollary 1 presumes all agents choose an interior labor supply at the elected tax rate. The condition laid out in (14) is not sufficent to rule out corner solutions for some agents. The condition in Corollary 2, on the other hand, is sufficent to rule out corner solutions for everyone (see Lemma (1)).

${ }^{20}$ Obviously, our intention here is not to conduct a full-blown calibration exercise, but simply to illustrate the wide scope of applicability of our contrarian result for the Meltzer-Richard model.
} 
lognormal distribution, i.e., $\ln e \sim \mathcal{N}(\mu, \lambda)$ where we set $\mu=0 .{ }^{21,22}$ We have numerically verified that as $\lambda$ is increased from 0 to 1 , the ratio of the effective time endowment of the mean to median agent, $(1+\bar{e}) /\left(1+e^{m}\right)$ goes from 1 to 1.32 and fundamental inequality in $e$ (as measured by the Gini coefficient) increases monotonically, roughly between 0 and 0.52 . Pre-tax income Ginis for most countries lie in the 0.25-0.5 range. The ratio of post-policy mean to median income generated by the model runs from 1 to 1.22 , roughly in line with U.S. data. The parametric choices we consider, however, produce a social spending-to-GDP ratio (captured here by $\left.\tau^{m}\right)$ in the range of $(0-46 \%)$, which is larger than the range of OECD estimates $(2-12 \%)$ for the same. ${ }^{23}$ However, if government spending includes more items than direct redistributive spending, our ratios would lie well within the observed range. We plot various variables of interest as functions of $\lambda \in(0,1)$ for three different values of $\sigma$,

\footnotetext{
${ }^{21} \mathrm{~A}$ few words about this choice are in order. First, while a fair bit is known about the pre-tax income distribution in the U.S., say, not much is known about fundamental inequality, much less the fundamental time-endowment distribution, underlying our results. Second, post tax/transfer income data for the entire U.S. population is difficult to come by. Much of what we know in this regard comes from I.R.S records, and is largely restricted to information about the top decile. Third, it appears no standard distribution does a great job of capturing the entire U.S. income distribution. As Piketty and Saez (2003) and others point out, the Pareto distribution works best only for the top two deciles while much of the action in our paper happens in the lower deciles. Cowell (2012) argues the lognormal distribution is a better fit for the bottom $80 \%$, and hence we adopt it, somewhat uncritically, as our distribution of choice for $e$.

${ }^{22}$ The lognormal density is given by $\frac{\exp \left\{-(\ln e-\mu)^{2} / 2 \lambda^{2}\right\}}{y \lambda \sqrt{2 \pi}}$, its mean by $\exp \left(\mu+0.5 \lambda^{2}\right)$, its median by $\exp (\mu)$, and skewness by $\exp \left(\lambda^{2}\right)+2\left(\sqrt{\exp \left(\lambda^{2}\right)}+1\right)$.

${ }^{23}$ Available at http://www.oecd-ilibrary.org/statistics
} 
$\sigma=0.80,0.99$, and 1.50

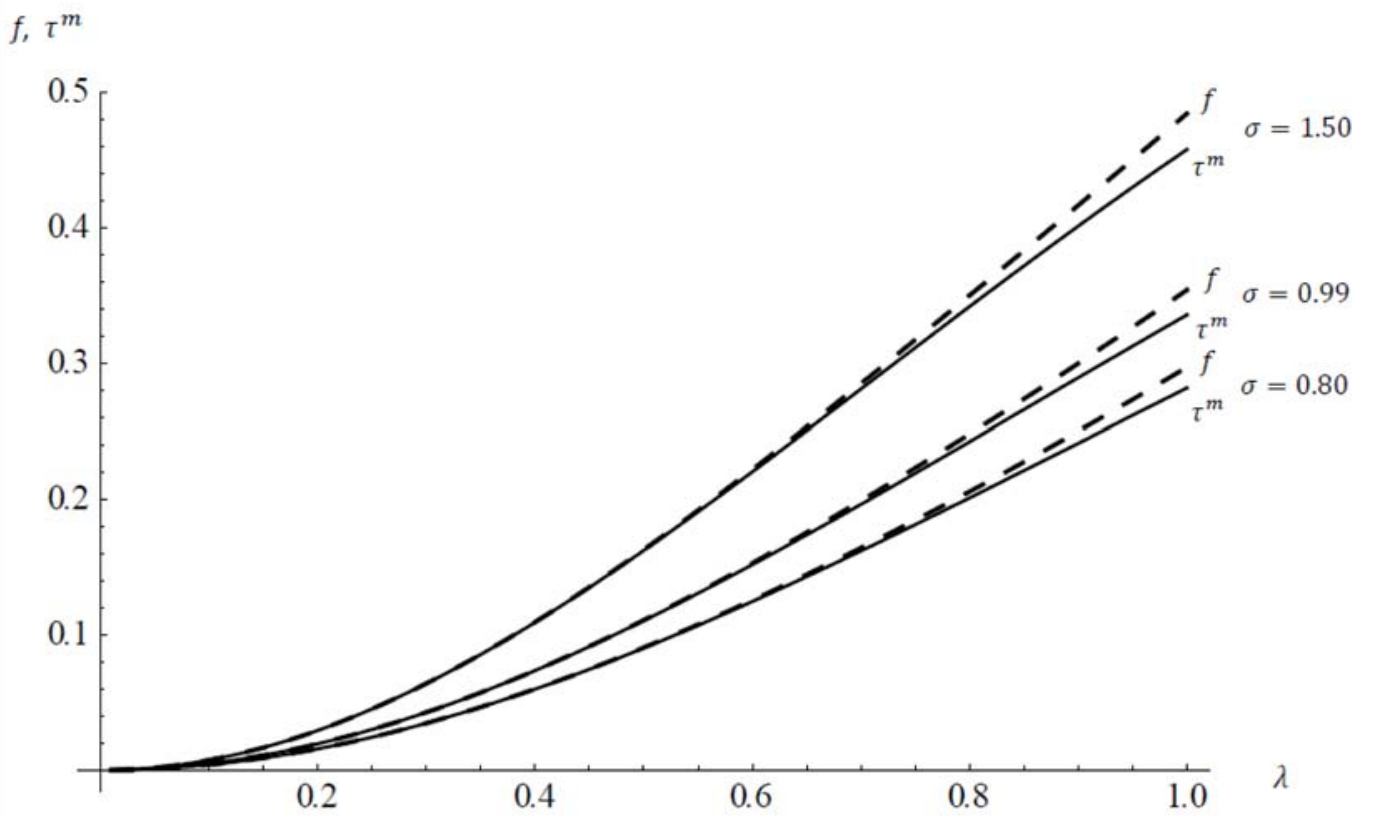

Figure 3a: $\tau^{m}$ and $f$ against $\lambda$ (for $\sigma=0.80,0.99,1.50$ )

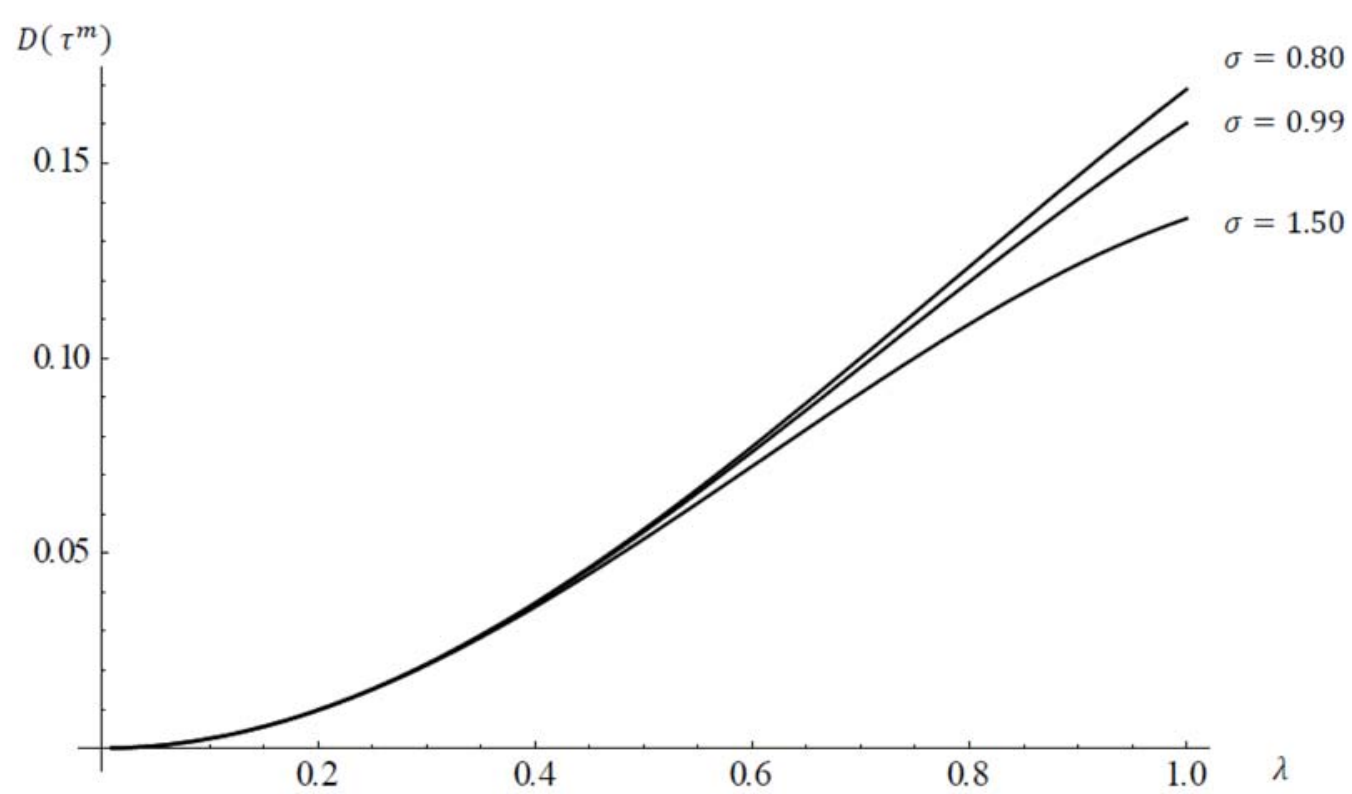

Figure 3b: $\mathcal{D}^{m}\left(\tau^{m}\right)$ against $\lambda($ for $\sigma=0.80,0.99,1.50$ ) 
Clearly, in Figure 3a, the elected tax rate and transfer rises with $\lambda$ and also with $\sigma$. As shown in Figure 3b, the median agent earns more income pre tax/transfer: $D\left(\tau^{m}\right)>0$. From Figure 3c, it is apparent that as inequality rises, the median voter's own labor income, $\left(1-\tau^{m}\right) l^{m}$ falls while transfer income, $f$ rises, making the latter a larger fraction of the agent's total income, $\left(1-\tau^{m}\right) l^{m}+f$. However, as this figure shows, transfer income only becomes the bulk of the median voter's overall income when $\lambda$ is sufficiently high, and that too only for $\sigma=1.50$ (for $\lambda \gtrsim 0.93$ ).

$f,\left(1-\tau^{m}\right) l^{m}$

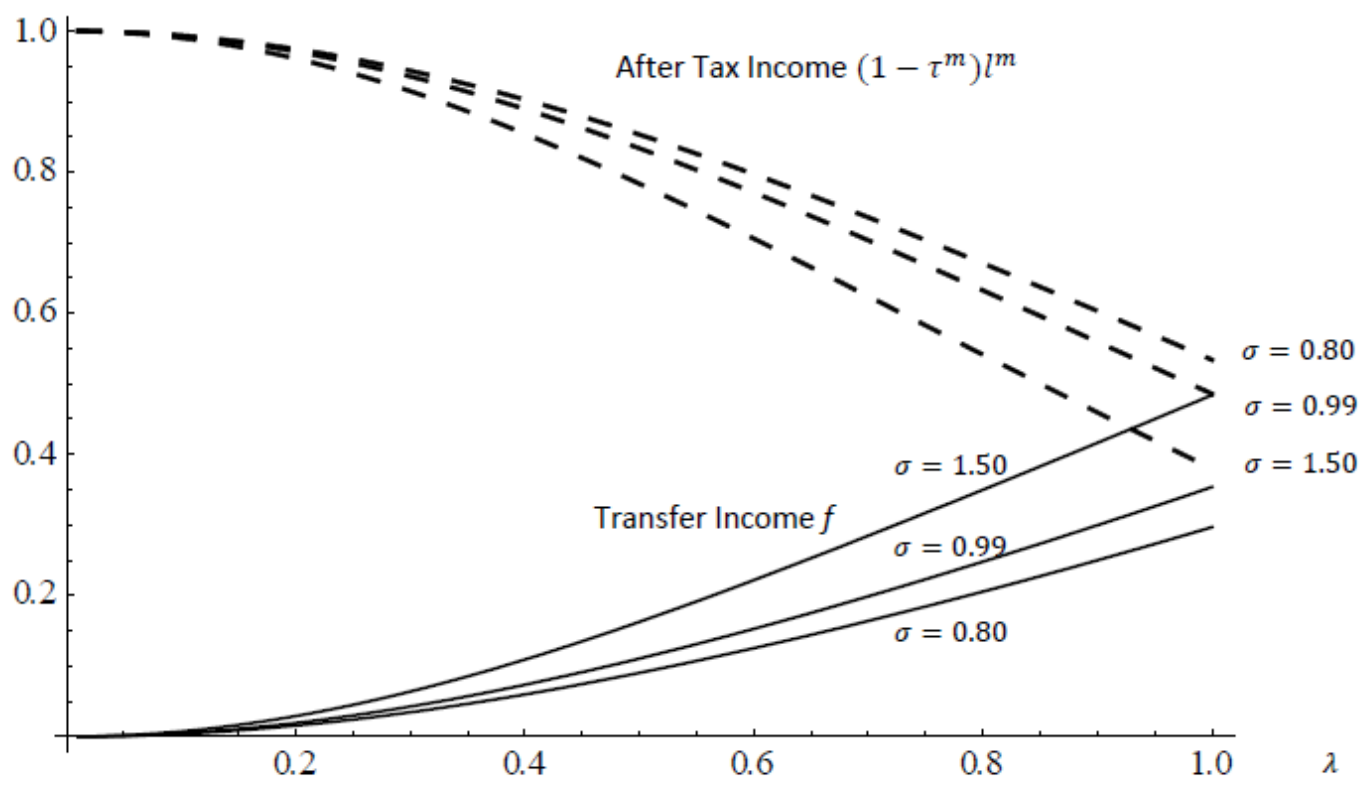

Figure 3c: Median own labor income and transfer income (for $\sigma=0.80,0.99,1.5$ )

A key point made in Section 2.2 - the median voter is willing to accept a less than onefor-one swap of labor income for labor-free transfer income - is illustrated in Figure 3d, for the case $\sigma=0.99$ and $\lambda$ increasing from 0 to 1 . Here, this trade-offs in income - see Figure 1a and the surrounding discussion - is summarized by the ratio $\frac{O F}{O F+E G}$, where, recall, $O F$ is the amount of transfer income received, and $O F+E G$, the labor income given up, under 
redistribution. This ratio, for the median voter, is shown in the figure as the center plot of the top three lines, starting at 0.65 when $\lambda=0$ and gradually rising as $\lambda$ increases. Figure $3 \mathrm{~d}$ also shows the plight of the mean voter (the plot that is negatively sloped as $\lambda$ rises) and that of the agent with the lowest endowment, $e^{i}=\underline{\xi}=0$. In the case of the latter, the ratio $\frac{O F}{O F+E G}$ hovers near 1 (and only exceeds 1 for $\lambda>0.55$ ) for the span for $\lambda$ we consider.

Figure 3d also shows the relative gains in leisure $\left(\frac{E^{\prime} G^{\prime}}{O E^{\prime}}\right)$ for these three agents, where $O E^{\prime}$ is the amount of leisure the agent chooses sans redistribution and $E^{\prime} G^{\prime}$ is the additional leisure the agent enjoys under the redistributive policy. These are shown in the bottom three plots of Figure 3d. As evident, the gains to redistribution for all agents are measured primarily in terms of greater leisure, and the relative gains are greatest for the poorest agents.

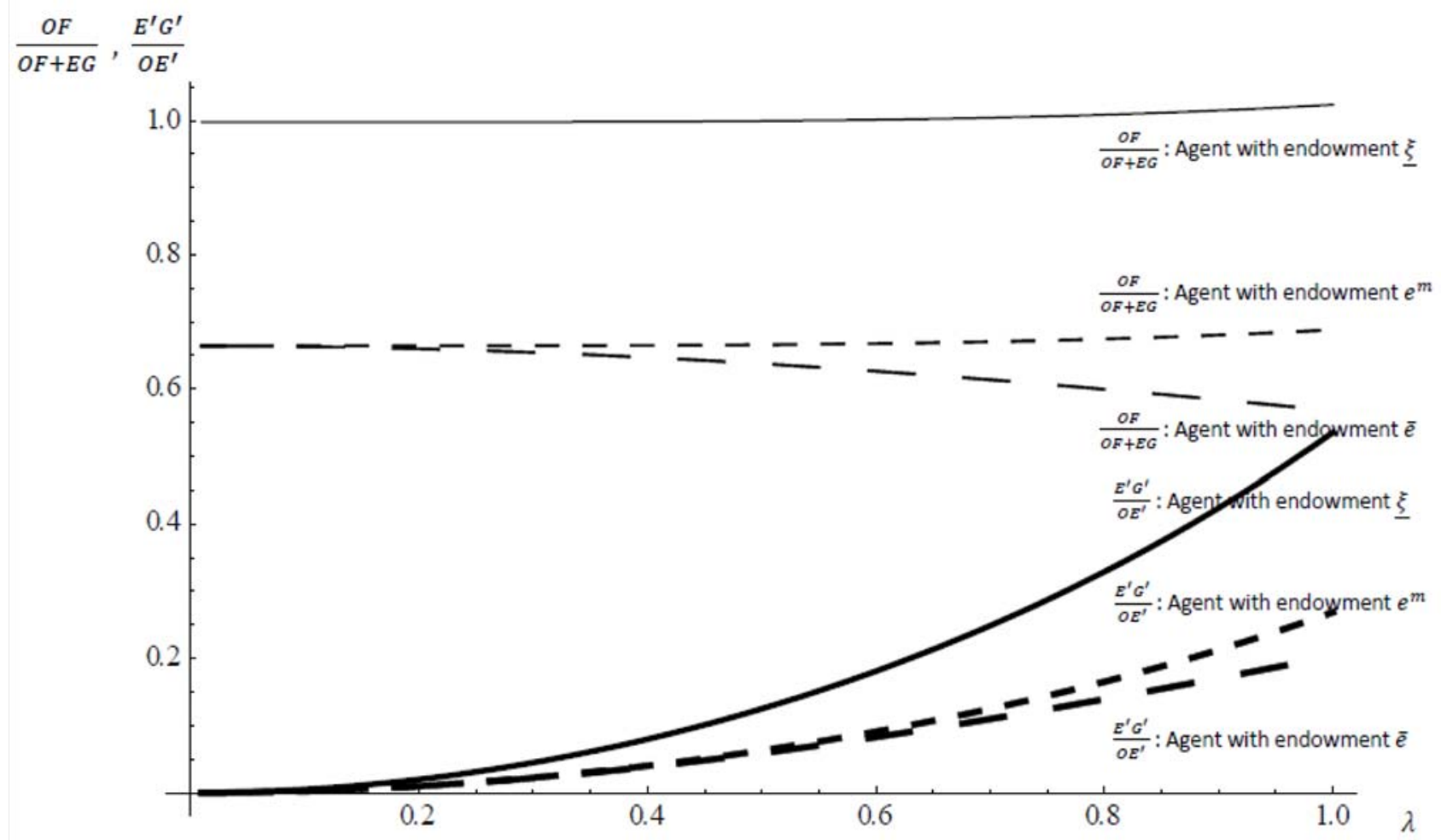

Figure 3d: Swapping own labor income for transfer income, $\sigma=0.99$ 
We have verified - for $\lambda \in(0,1)$ and $\sigma=0.80$ and $\sigma=0.99$ - the fraction of agents that is better off income-wise with policy is nearly zero (shown in Figure 3e as a horizontal line tracing the $\mathrm{X}$-axis). In this case, nearly everyone is hurt income-wise by the tax-transfer policy. $^{24}$

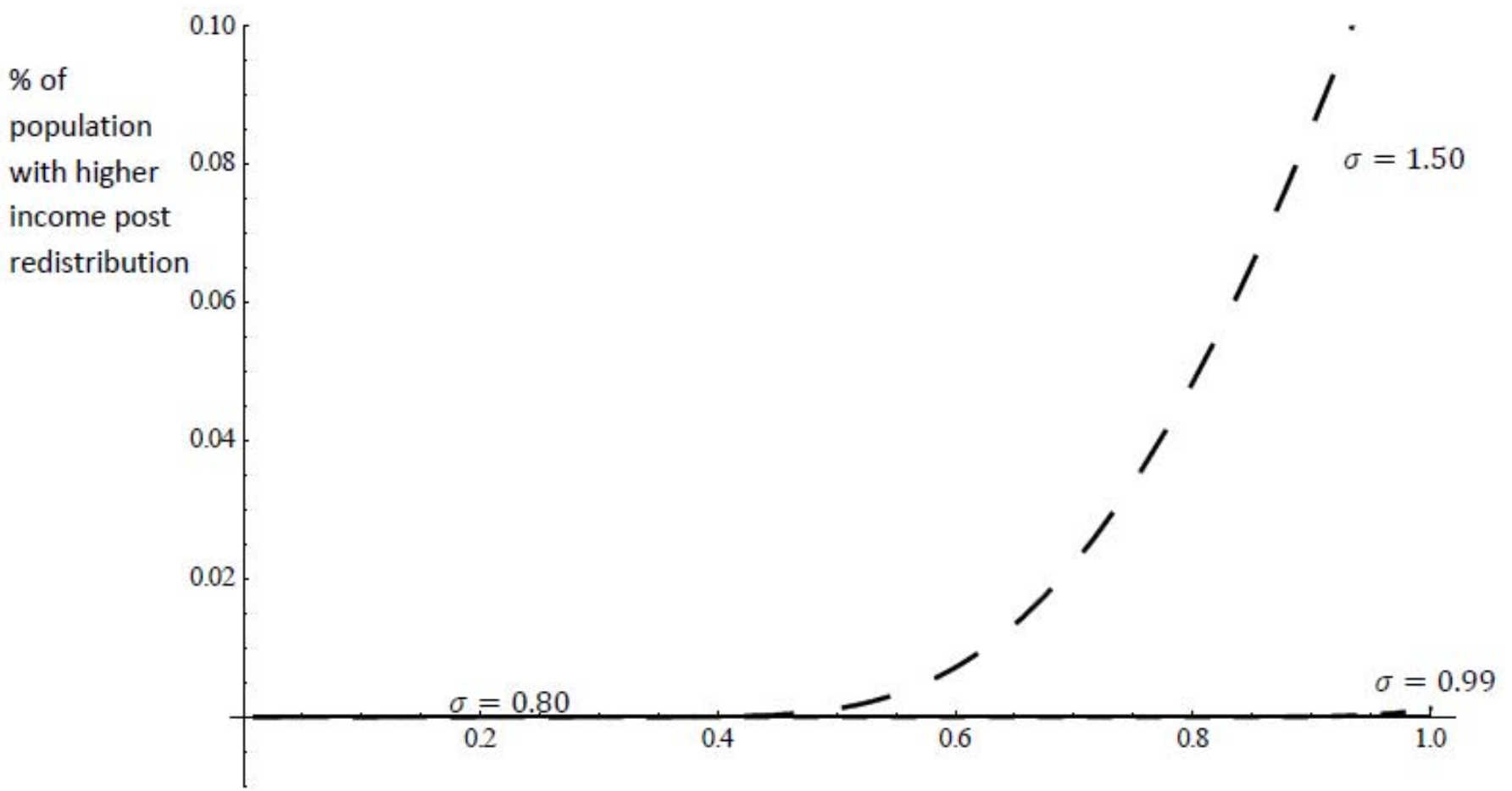

Figure 3e: Fraction of agents made better off income-wise with policy (for $\sigma=0.8,0.99,1.5$ )

\footnotetext{
${ }^{24}$ We should note our result that no one may emerge with greater income post-transfer is an artifact of our assumption of the lower bound on the endowment $\underline{\xi}$, specifically, that $\underline{\xi}=0$. Suppose, for example, our distribution permitted values for $\underline{\xi}$ less than 0 , such as -1 . In that case, some agents will emerge better off, income-wise, with transfers, as long as there is some right-skewness in the distribution. Such agents will have very little income and leisure to begin with (without redistribution), and so may well have more income and leisure post-transfer. There will also be a set of agents within these low $e^{i}$ agents that chose not to work under redistribution.
} 


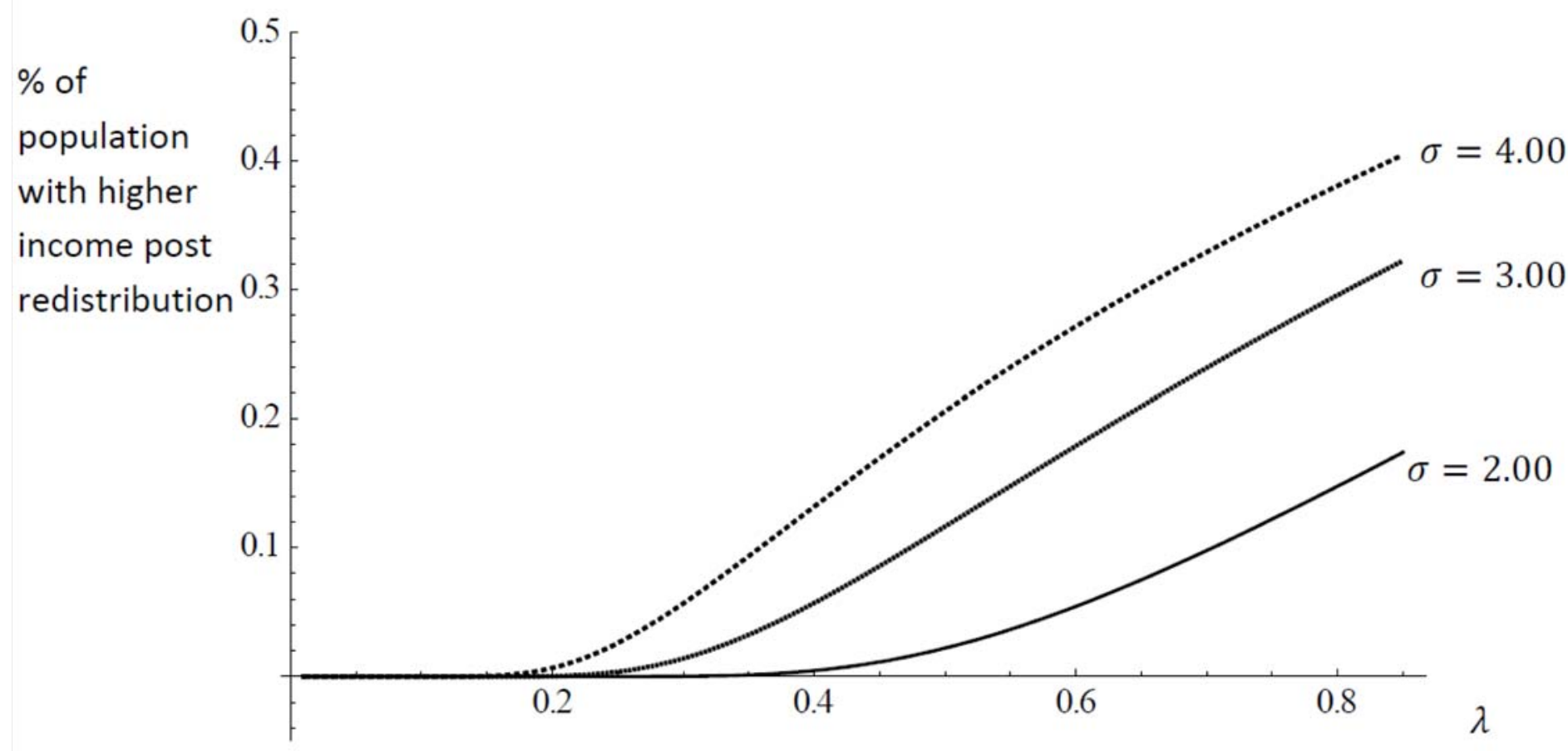

Figure 3f: Fraction of agents made better off income-wise with policy (for $\sigma=2,3,4$ ) Figure 3e also depicts the same for $\sigma=1.50$; in this case, no more than $15 \%$ of the population is better off income-wise with the redistribution policy. For higher, possibly less empiricallyrelevant values of $\sigma$, a greater portion of the population is made better off income-wise as $\lambda$ rises - see Figure 3f; yet, it may never exceed $50 \%$ of the electorate. ${ }^{25}$ These examples, and many others we have generated but not reported, bolsters the claim that our result the median voter (and many poorer voters) suffer income losses with redistribution — is widespread in the Meltzer-Richard model.

It bears emphasis here that our results arise from within a voting equilibrium, one in which the median voter chooses her income. As is clear, textbook substitution and income effects are present but here they are far more involved than usual because the agent internalizes

\footnotetext{
${ }^{25}$ Figure 3f utilizes a smaller spread in $\lambda$ in order to ensure labor supply decisions are consistent with interior solutions, an assumption we have utilized throughout our analysis.
} 
these effects in her choice of the tax rate. Additionally, her choice unleashes an economy-wide wealth effect due to the transfer, whose size in turn, is ultimately in her hands.

Despite the fact that redistribution results in less income for the median voter and others, it does achieve what it sets out to do - namely, reduce the amount of income inequality - as the following proposition attests.

Proposition 3 Redistribution reduces income inequality.

In the absence of redistributive policies, the income gap between any two agents $i, j$, is simply, $\left(e^{i}-e^{j}\right) / 2$. With redistribution, $y_{\tau}^{i}-y_{\tau}^{j} \equiv(1-\tau)\left(l\left(e^{i}, \tau, f\right)-l\left(e^{j}, \tau, f\right)\right)=$ $\frac{(1-\tau)(1-\tau)^{\frac{1}{\sigma}}\left(e^{i}-e^{j}\right)}{\left[(1-\tau)+(1-\tau)^{\frac{1}{\sigma}}\right]}$. But $\frac{(1-\tau)(1-\tau)^{\frac{1}{\sigma}}}{\left[(1-\tau)+(1-\tau)^{\frac{1}{\sigma}}\right]}<\frac{1}{2}$, i.e., $2(1-\tau)(1-\tau)^{\frac{1}{\sigma}}<(1-\tau)+(1-\tau)^{\frac{1}{\sigma}}$, since $(1-\tau)+(1-\tau)^{\frac{1}{\sigma}}-2(1-\tau)(1-\tau)^{\frac{1}{\sigma}}=(1-\tau)\left(1-(1-\tau)^{\frac{1}{\sigma}}\right)+(1-\tau)^{\frac{1}{\sigma}} \tau>0$.

Redistribution always reduces the income gap between agents; i.e., $y_{0}^{i}-y_{0}^{j}>y_{\tau}^{i}-y_{\tau}^{j}$ for any $i, j$, with $e^{i}>e^{j}$. At its core, then, income redistribution in the Meltzer-Richard model isn't necessarily about allowing some to receive more income than they would in its absence; it is about evening out disparities in income.

\section{Concluding remarks}

Much of the literature on income distribution in democratic environments takes off from Meltzer and Richard (1981). The Meltzer-Richard model analyzes a very simple redistributive scheme. The tax instrument is a proportional income tax in an economy where heterogeneous agents have different innate productivities (and hence, income), and choose to work different amounts. The tax revenue is redistributed lump sum to everyone. In such an 
environment, if the median voter has lower pre-tax income than the average voter, Meltzer and Richard showed that the former would favor governments that implement a positive tax rate, one which brings her a positive net transfer. We ask, how does her post-tax income compare to her pre-tax income? Somewhat curiously, we find that the median voter (and many poorer voters) may end up with a lower post-tax income. If it is not the prospect of receiving higher income, what drives the median voter to support such income redistribution? The answer, quite simply, is leisure. A higher tax reduces the incentive to supply labor, reduces labor income and, as we have seen, potentially reduces post-redistribution income; the only saving grace is additional leisure time financed by the income transfer. In sum, while the Meltzer-Richard model has a clear message explaining the strong support for income redistributive policies in high before-tax income inequality environments, the basis for that support is often leisure, not income. At least within the narrow confines of the Meltzer-Richard environment, - static, single good, linear taxation, and lump-sum, untargeted redistribution - democracy is well-suited for evening out inequality, but not necessarily for lifting incomes of the poor.

Two final remarks are in order here. First, while to the best of our knowledge, no one has actually suggested that redistribution must result in higher income for agents at or below the median, it seemed self-evident to us (and possibly others) until we found otherwise. Second, our result has some bearing on the literature on transfer paradoxes in international economics. There, a transfer from one country to another, by mangling the terms of trade, can immiserize the recipient and enrich the donor. In such models though, the recipient does not choose to get the transfer; it is simply thrust upon the recipient. By contrast, in the Meltzer-Richard model, the recipient median voter chooses the transfer herself, but 
paradoxically, redistribution leaves her with less not more income.

In future work, it may be interesting to explore if and how the sorts of concerns raised in this paper may have implications for why democracies on two sides of the Atlantic seem so far apart when it comes to taxes, leisure, and income redistribution. 


\section{Appendix}

\section{A C.E.S. preferences}

Let

$$
W(c, x)=\left\{\begin{array}{c}
\frac{c^{1-\sigma}}{1-\sigma}+\frac{x^{1-\sigma}}{1-\sigma}, \sigma>0, \sigma \neq 1 \\
\ln c+\ln x \text { if } \sigma=1
\end{array},\right.
$$

For these preferences, an interior solution for work is

$$
l\left(e^{i}, \tau, f\right)=\frac{(1-\tau)^{\frac{1}{\sigma}}\left(1+e^{i}\right)-f}{\left[(1-\tau)+(1-\tau)^{\frac{1}{\sigma}}\right]}
$$

Clearly, $l\left(e^{i}, \tau, f\right) \geq 0$ if (4) holds. Assuming (4) holds for all agents, the tax base $\mathcal{L} \equiv$ $\int l(e, \tau, f) d \mathcal{G}(e)$ is $\bar{l}=\frac{(1+\bar{e})-(1-\tau)^{-\frac{1}{\sigma}} f}{\left[1+(1-\tau)^{-\frac{1}{\sigma}}\right]}$, where $\bar{l}$ is obtained from (15) by evaluating $e^{i}$ at the mean $\bar{e}$. Since $f=\tau \mathcal{L}$, we can solve for $f$ and $\bar{l}$ in terms of the tax rate only, $f=$ $\left[\tau(1+\bar{e})(1-\tau)^{\frac{1}{\sigma}}\right] /\left[(1-\tau)^{\frac{1}{\sigma}}+1\right]$ and $\bar{l}=\left[(1+\bar{e})(1-\tau)^{\frac{1}{\sigma}}\right] /\left[(1-\tau)^{\frac{1}{\sigma}}+1\right]$. The labor and leisure choices for agent $i$ assuming (4) are then given by

$$
l\left(e^{i}, \tau\right)=(1-\tau)^{\frac{1}{\sigma}} \frac{\left(1+e^{i}\right)\left((1-\tau)^{\frac{1}{\sigma}}+1\right)-\tau(1+\bar{e})}{\left((1-\tau)^{\frac{1}{\sigma}}+1\right)\left((1-\tau)^{\frac{1}{\sigma}}+(1-\tau)\right)}
$$

and

$$
x\left(e^{i}, \tau\right)=\frac{e^{i}\left((1-\tau)^{\frac{1}{\sigma}}+(1-\tau)\right)+\left(\bar{e}-e^{i}\right) \tau(1-\tau)^{\frac{1}{\sigma}}+\left((1-\tau)^{\frac{1}{\sigma}}+(1-\tau)\right)}{\left((1-\tau)^{\frac{1}{\sigma}}+1\right)\left((1-\tau)^{\frac{1}{\sigma}}+(1-\tau)\right)} .
$$

For future use, note that

$$
\frac{d l\left(e^{i}, \tau\right)}{d \tau}=-\frac{1}{\sigma} \frac{(1-\tau)^{\frac{1}{\sigma}-1}\left[\left(1+e^{i}\right)(1-\tau)+f\right]}{\left[(1-\tau)^{\frac{1}{\sigma}}+(1-\tau)\right]^{2}}<0 .
$$

Using the solution for $f$ above, (4) reduces to $\left(1+e^{i}\right) \geq \frac{\tau}{(1-\tau)^{\frac{1}{\sigma}}+1}(1+\bar{e})$. Since $l^{i}$ (and $\left.x^{i}\right)$ are linear and increasing in $e^{i}$, setting $e^{i}=\underline{\xi}$ (the minimum of the support of $e$ ) allows us to define a range of "permissible" tax rates for which the labor supply of each agent is positive: 
$(1+\underline{\xi}) \geq \frac{\tau}{(1-\tau)^{\frac{1}{\sigma}}+1}(1+\bar{e})$. The right-hand side of this inequality is strictly increasing in $\tau$, equal to 0 when $\tau=0$ and is $(1+\bar{e})$ when $\tau=1$. Therefore, there exists a unique $\tau^{*} \in(0,1)$ such that

$$
(1+\underline{\xi}) \gtreqless \frac{\tau}{(1-\tau)^{\frac{1}{\sigma}}+1}(1+\bar{e}) \text { for } \tau \gtreqless \tau^{*} .
$$

It follows that when $\tau \in\left[0, \tau^{*}\right)$, everyone chooses an interior labor supply and in this range, the tax base (the average labor supply) equals the labor supply of the average timeendowment agent.

\section{B Proof of (11)}

Using (10) and (16), it follows that

$$
\tau=\frac{\frac{\left(1+e^{i}\right)-\frac{\tau(\bar{e}+1)(1-\tau)^{-\frac{1}{\sigma}}}{1+(1-\tau)-\frac{1}{\sigma}}}{1+(1-\tau)^{1-\frac{1}{\sigma}}}-\frac{1+\bar{e}}{1+(1-\tau)^{-\frac{1}{\sigma}}}}{-\frac{(1+\bar{e})}{\sigma\left((1-\tau)^{\frac{1}{\sigma}(\sigma-1)}+1\right)^{2}{ }^{2}(1-\tau)^{\frac{2}{\sigma}}}\left((1-\tau)^{\frac{1}{\sigma}}(1-\sigma)+\frac{\tau}{1+(1-\tau)^{-\frac{1}{\sigma}}}\left(\frac{1}{(1-\tau)^{1-\frac{1}{\sigma}}}+\sigma\right)\right)-(1-\tau)^{\frac{1}{\sigma}} \frac{\left(1+e^{i}\right)\left((1-\tau)^{\frac{1}{\sigma}}+1\right)-\tau(1+\bar{e})}{\left((1-\tau)^{\frac{1}{\sigma}}+1\right)\left((1-\tau)^{\frac{1}{\sigma}}+(1-\tau)\right)} \frac{(1-\tau)^{-\frac{1}{\sigma}}}{1+(1-\tau)^{1-\frac{1}{\sigma}}}} .
$$

The numerator reduces to $\frac{1}{1+(1-\tau)^{1-\frac{1}{\sigma}}}\left(\left(1+e^{i}\right)-(1+\bar{e})\right)$ and the denominator to

$$
-\frac{(1+\bar{e})}{\sigma\left(1+(1-\tau)^{1-\frac{1}{\sigma}}\right)^{2}(1-\tau)^{\frac{2}{\sigma}}}\left(\frac{1+(1-\tau)^{1-\frac{1}{\sigma}}-\sigma(1-\tau)\left(1+(1-\tau)^{-\frac{1}{\sigma}}\right)}{\left(1+(1-\tau)^{-\frac{1}{\sigma}}\right)(1-\tau)^{1-\frac{1}{\sigma}}}\right)-\frac{(1-\tau)^{-\frac{1}{\sigma}}\left(1+e^{i}\right)}{\left(1+(1-\tau)^{1-\frac{1}{\sigma}}\right)^{2}}
$$

Then, (19) reduces to

$$
\begin{aligned}
& -\frac{\tau(1+\bar{e})}{\sigma\left(1+(1-\tau)^{1-\frac{1}{\sigma}}\right)^{2}(1-\tau)^{\frac{2}{\sigma}}}\left(\frac{1+(1-\tau)^{1-\frac{1}{\sigma}}-\sigma(1-\tau)\left(1+(1-\tau)^{-\frac{1}{\sigma}}\right)}{\left(1+(1-\tau)^{-\frac{1}{\sigma}}\right)(1-\tau)^{1-\frac{1}{\sigma}}}\right)+\frac{(1+\bar{e})}{1+(1-\tau)^{1-\frac{1}{\sigma}}} \\
= & \frac{1}{1+(1-\tau)^{1-\frac{1}{\sigma}}}\left(1+e^{i}\right)+\frac{\tau(1-\tau)^{-\frac{1}{\sigma}}}{\left(1+(1-\tau)^{1-\frac{1}{\sigma}}\right)^{2}}\left(1+e^{i}\right)
\end{aligned}
$$


Furthermore, the right hand side of (20) simplifies to $\frac{\left(1+(1-\tau)^{-\frac{1}{\sigma}}\right)\left(1+e^{i}\right)}{\left(1+(1-\tau)^{1-\frac{1}{\sigma}}\right)^{2}}$ and the left hand side to

$$
\begin{aligned}
= & -\frac{1}{\sigma\left((1-\tau)^{\frac{1}{\sigma}(\sigma-1)}+1\right)^{2}} \frac{1+\bar{e}}{(1-\tau)^{\frac{1}{\sigma}(\sigma+2)}\left(\frac{1}{(1-\tau)^{\frac{1}{\sigma}}}+1\right)} \times \\
& {\left[(\sigma-\tau)(1-\tau)+\sigma(1-\tau)^{\frac{2}{\sigma}}(1-\tau)+(1-\tau)^{\frac{1}{\sigma}}(2 \sigma-\tau-2 \sigma \tau)\right] }
\end{aligned}
$$

So the equation which determines $\tau^{i}$ is rewritten as

$$
\begin{aligned}
& \sigma\left(1+\left(1-\tau^{i}\right)^{-\frac{1}{\sigma}}\right)\left(\left(1-\tau^{i}\right)^{\frac{\sigma+2}{\sigma}}\left(\frac{1}{\left(1-\tau^{i}\right)^{\frac{1}{\sigma}}}+1\right)\right) \frac{\left(1+e^{m}\right)}{(1+\bar{e})} \\
= & \left(\sigma-\tau^{i}\right)\left(1-\tau^{i}\right)+\sigma\left(1-\tau^{i}\right)^{\frac{2}{\sigma}}\left(1-\tau^{i}\right)+\left(1-\tau^{i}\right)^{\frac{1}{\sigma}}\left(2 \sigma-\tau^{i}-2 \sigma \tau^{i}\right)
\end{aligned}
$$

Routine rearrangement yields

$$
\begin{aligned}
& \sigma\left(1+\left(1-\tau^{i}\right)^{\frac{1}{\sigma}}\right)^{2}\left(1-\tau^{i}\right) \frac{\left(1+e^{m}\right)}{(1+\bar{e})}=\left(\sigma-\tau^{i}\right)\left(1-\tau^{i}\right)+\sigma\left(1-\tau^{i}\right)^{1+\frac{2}{\sigma}}+\left(1-\tau^{i}\right)^{\frac{1}{\sigma}}\left(2 \sigma-\tau^{i}-2 \sigma \tau\right. \\
& \Leftrightarrow \tau^{i}\left(1-\tau^{i}\right)^{\frac{1}{\sigma}}+\tau^{i}\left(1-\tau^{i}\right)=\sigma\left(1-\frac{\left(1+e^{i}\right)}{(1+\bar{e})}\right)\left(1-\tau^{i}\right)\left[1+\left(1-\tau^{i}\right)^{\frac{2}{\sigma}}+2\left(1-\tau^{i}\right)^{\frac{1}{\sigma}}\right] \\
& \Leftrightarrow \tau^{i}\left(1-\tau^{i}\right)^{\frac{1}{\sigma}}+\tau^{i}\left(1-\tau^{i}\right)=\sigma\left(1-\frac{\left(1+e^{i}\right)}{(1+\bar{e})}\right)\left(1-\tau^{i}\right)\left(1+\left(1-\tau^{i}\right)^{\frac{1}{\sigma}}\right)^{2}
\end{aligned}
$$

which is (11).

\section{Proof of Lemma 1}

Let $h(\tau) \equiv \frac{\sigma}{(1+\sigma)}-\frac{\tau}{(1-\tau)^{\frac{1}{\sigma}}+1}$. It is easy to show $h^{\prime}(\tau)<0$, and that $h(0)=\frac{\sigma}{(1+\sigma)}$ and $h(1)=-\frac{1}{(1+\sigma)}$. Since $h(\tau)$ is continuous over $[0,1]$, there exists a value $\tau_{0}$ such that $h(\tau)>0$ for $\tau<\tau_{0}$ and $h(\tau) \leq 0$ for $\tau \geq \tau_{0}$. It follows that if the elected tax, $\tau^{m} \leq \tau_{0}$ for all $\sigma$, then any lower bound that satisfies $(1+\underline{\xi}) \geq \frac{\sigma(1+\bar{e})}{(1+\sigma)} \rightarrow(1+\underline{\xi})>\frac{\tau^{m}(1+\bar{e})}{\left(1-\tau^{m}\right)^{\frac{1}{\sigma}}+1}$. Further, since, by definition, $(1+\underline{\xi})=\frac{\tau^{*}}{\left(1-\tau^{*}\right)^{\frac{1}{\sigma}}+1}(1+\bar{e})$, we can conclude the lower bound agent is not at a corner.

We can characterize the tax rate $\tau_{0}$ as a fixed point of the following equation:

$$
\tau=\frac{\sigma}{1+\sigma}\left(1+(1-\tau)^{\frac{1}{\sigma}}\right)
$$

Characterizing the elected tax rate is more difficult. However, from the first-order condition for the tax rate, $\frac{\partial W^{i}(\tau)}{\partial \tau}=U_{c}().\left[\frac{d f}{d \tau}-l\left(e^{i}, \tau, f\right)\right]$, the elected tax rate will be less 
than the tax rate that maximizes the transfer as long as $l\left(e^{m}, \tau, f\right)>0$. The transfer is $f=\frac{\tau(1+\bar{e})(1-\tau)^{\frac{1}{\sigma}}}{(1-\tau)^{\frac{1}{\sigma}}+1}$. Differentiating $f$, the tax rate that maximizes the transfer satisfies:

$$
\tau=\frac{\sigma}{1+\sigma+\sigma(1-\tau)^{\frac{1}{\sigma}}}\left(1+(1-\tau)^{\frac{1}{\sigma}}\right)
$$

Since the right-hand side of (22) is everywhere below that of the right-hand side of (21), the elected tax rate must be below $\tau_{0}$. Hence, if the condition $(1+\underline{\xi}) \geq \frac{\sigma(1+\bar{e})}{(1+\sigma)}$ is met, $(1+\underline{\xi})>\frac{\tau^{m}(1+\bar{e})}{\left(1-\tau^{m}\right)^{\frac{1}{\sigma}}+1}$ will hold as well.

\section{Proof of Proposition 2}

Proof for the same for $\sigma=3$. The expression $D^{i}(\tau)$ is increasing in $e^{i}$. Let $\sigma=3$. In this case,

$\lim _{e^{i} \rightarrow \frac{3 \bar{e}-1}{1+3}} D^{i}(\tau)=\frac{(1+\bar{e})\left[2 \tau(1-\tau)^{\frac{1}{3}}\left(1-(1-\tau)^{\frac{1}{3}}\right)+\left(3(1-\tau)-3(1-\tau)^{\frac{2}{3}}+\tau(1-\tau)^{\frac{1}{3}}\right)\right]}{8\left(1+(1-\tau)^{\frac{1}{3}}\right)\left((1-\tau)+(1-\tau)^{\frac{1}{3}}\right)}$.

The sign of the denominator is positive for $\tau \in(0,1)$. The first expression in the square brackets in the numerator, $2 \tau(1-\tau)^{\frac{1}{3}}\left(1-(1-\tau)^{\frac{1}{3}}\right) \geq 0$ for $\tau \in[0,1]$. The second term, $3(1-\tau)-3(1-\tau)^{\frac{2}{3}}+\tau(1-\tau)^{\frac{1}{3}}$ is also positive for all $\tau \in[0,1]$. To see this latter point, let $z \equiv(1-\tau)^{\frac{1}{3}}$, so $\tau=1-z^{3}$. We can then rewrite $3(1-\tau)-3(1-\tau)^{\frac{2}{3}}+\tau(1-\tau)^{\frac{1}{3}}$ as $z\left(3 z^{2}-3 z+1-z^{3}\right) \equiv v(z)$. Note that $v(0)=0$. To determine the sign of $v(z)$ for $z \in(0,1]$, it is sufficient to determine the sign of $3 z^{2}-3 z+1-z^{3}$. Note that $\frac{\partial\left(3 z^{2}-3 z+1-z^{3}\right)}{\partial z}=$ $-3(z-1)^{2}<0$, so $\left(3 z^{2}-3 z+1-z^{3}\right)$ is smallest at $z=1$. At $z=1,3 z^{2}-3 z+1-z^{3}=0$. It follows that for $0<z<1, v(z)>0$. Hence, $D^{i}(\tau)>0$ for all $\tau \in(0,1)$.

Notice, the right-hand side of the inequality $e^{i} \geq \frac{\sigma \bar{e}-1}{1+\sigma}$ is increasing in $\sigma$. Therefore, if $e^{i} \geq \frac{3 \bar{e}-1}{1+3}$, the inequality $e^{i} \geq \frac{\sigma \bar{e}-1}{1+\sigma}$ is satisfied for all values of $\sigma<3$. It then follows from that $D^{i}(\tau) \geq 0$ for all $\tau \in[0,1]$ for $0 \leq \sigma \leq 3$.

\section{E $\quad$ Proof of Lemma 3}

We have $y_{0}^{i} \equiv l\left(e^{i}, 0,0\right), y_{\tau}^{i} \equiv(1-\tau) l\left(e^{i}, \tau, f\right)+f$, and $D^{i}(\tau) \equiv y_{0}^{i}-y_{\tau}^{i}$. The easiest way to show Lemma 3 is to show how $D^{i}(\tau)$ changes for a change in $\sigma$ for a given transfer $f$, and then show how $\sigma$ affects $f$ and ultimately $D^{i}(\tau)$. 
From $(15)$, we have $y_{0}^{i}=\frac{1+e^{i}}{2}$, and $y_{\tau}^{i}=(1-\tau) \frac{(1-\tau)^{\frac{1}{\sigma}}\left(1+e^{i}\right)-f}{\left[(1-\tau)+(1-\tau)^{\frac{1}{\sigma}}\right]}+f$. Such that $\frac{\partial}{\partial \sigma} D^{i}(\tau, f)=$ $\frac{\partial}{\partial \sigma} y_{\tau}^{i}=\frac{\partial}{\partial \sigma}\left(\frac{(1-\tau)(1-\tau)^{1+\frac{1}{\sigma}}\left(1+e^{i}\right)}{(1-\tau)+(1-\tau)^{\frac{1}{\sigma}}}\right)-\frac{(1-\tau)^{\frac{1}{\sigma}}}{(1-\tau)+(1-\tau)^{\frac{1}{\sigma}}} \frac{\partial f}{\partial \sigma}$. For a given transfer $f$ then, the change in $y_{0}^{i}-y_{\tau}^{i}$ resulting from a marginal change in $\sigma$ is

$$
\frac{(1-\tau) \ln (1-\tau)}{\sigma^{2}} \frac{(1-\tau)^{\frac{1}{\sigma}}\left((1-\tau)\left(1+e^{i}\right)+f\right)}{\left((1-\tau)^{\frac{1}{\sigma}}+(1-\tau)\right)^{2}}<0
$$

since $\ln (1-\tau)<0$ for any $1-\tau<1$.

Next, note that the difference $y_{0}^{i}-y_{\tau}^{i}$ is decreasing in $f: \frac{\partial\left(y_{0}^{i}-y_{\tau}^{i}\right)}{\partial \sigma}=-\frac{(1-\tau)^{\frac{1}{\sigma}}}{(1-\tau)^{\frac{1}{\sigma}+(1-\tau)}}<0$. Finally, since $f=\tau\left[(1+\bar{e})(1-\tau)^{\frac{1}{\sigma}}\right] /\left[(1-\tau)^{\frac{1}{\sigma}}+1\right], \frac{\partial f}{\partial \sigma}=-\frac{\tau \ln (1-\tau)}{\sigma^{2}} \frac{(1-\tau)^{\frac{1}{\sigma}}(1+\bar{e})}{\left((1-\tau)^{\frac{1}{\sigma}}+1\right)^{2}}>0$. It follows that $D^{i}(\tau)$ is decreasing in $\sigma$. 


\section{References}

[1] Alesina, A., and George-Marios Angeletos. "Fairness and Redistribution." American Economic Review 95(4), 2005, 960-980.

[2] Azzimonti, M., de Francisco, E., and Per Krusell. "Median-voter Equilibria in the Neoclassical Growth Model under Aggregation." Scandinavian Journal of Economics 108 (4), 2006, 587-606.

[3] Azzimonti, M., de Francisco, E., and Per Krusell. "Aggregation and Aggregation." Journal of the European Economic Association 6(2-3), 2008, 381-394.

[4] Boadway R. and M. Keen. "Redistribution," in Handbook of Income Distribution: Volume 1. Edited by A. B. Atkinson and F Bourguignon, Amsterdam: North Holland, 2000, 677-789.

[5] Borge, L., and J. Jorn Rattso. "Income Distribution and Tax Structure: Empirical Test of the Meltzer-Richard Hypothesis." European Economic Review 48(4), 2004, 805-826.

[6] Beramendi, P. and C. Anderson, editors. Democracy, Inequality, and Representation. New York: Russell Sage Foundation, 2008.

[7] The Economist. "Democracies and Debt," 1 September 2012.

[8] Georgiadis, A. and Alan Manning. "Spend it like Beckham? Inequality and Redistribution in the UK, 1983-2004." Public Choice, 151, 2012, 537-563.

[9] Gerring, J., S. C. Thacker, and Alfaro Rodrigo. "Democracy and Human Development." Journal of Politics, 74, 2012, 1-17.

[10] Hodler, R. "Leisure and Redistribution." European Journal of Political Economy, 24 (2), 2008 354-363.

[11] Iverson, T. "Democracy and Capitalism" in Oxford Handbook of Political Economy, edited by D. Wittman and B. Weingast, Oxford: Oxford University Press, 2006, 601623.

[12] Katzner, D. W. Static Demand Theory. New York: Macmillan, 1970. 
[13] Kenworthy, L. "Inequality and Sociology." American Behavioral Scientist (50), 2007, 584-602.

[14] Kenworthy, L., and Jonas Pontusson. "Rising Inequality and the Politics of Redistribution in Affluent Countries." Perspectives on Politics (3), 2005, 449-471.

[15] Krusell, P., and Jose-Victor Rios-Rull. "On the Size of U.S. Government: Political Economy in the Neoclassical Growth Model." American Economic Review 89 (5), 1999, 1156-1181.

[16] Lindqvist, E., and Robert Östling. "Identity and Redistribution." Public Choice, 155 (3-4), 2013, 469-491.

[17] Lupu, L and Jonas Pontusson. "The Structure of Inequality and the Politics of Redistribution." American Political Science Review, 105(2) 2011,. 316-336.

[18] Mulligan, C. B. "Economic Limits on "Rational" Democratic Redistribution." Working Papers 0107, Harris School of Public Policy Studies, University of Chicago, 2001.

[19] Meltzer, A. H., and Scott Richard. "A Rational Theory of the Size of Government." Journal of Political Economy 89(5), 1981, 914-27.

[20] Meltzer, A. H., and Scott F. Richard. "Tests of a Rational Theory of the Size of Government." Public Choice 41, 1983, 403-418.

[21] Persson, T., and G. Tabellini, Political Economics: Explaining Economic Policy. Cambridge: MIT, 2002a.

[22] Persson, T., and G. Tabellini. "Political Economics and Public Finance," in Handbook of Public Economics, Volume 3, edited by A.J. Auerbach and M. Feldstein, Amsterdam: North Holland, 2002b, 1549-1659.

[23] Pontusson J., and D. Rueda. "The Politics of Inequality: Voter Mobilization and Left Parties in Advanced Industrial States." Comparative Political Studies, 43(6), 2010, 675705.

[24] Shapiro, I. "Why the Poor Don't Soak the Rich: Notes on Democracy and Distribution," Daedalus 130(4), (2002), 118-28. 
[25] Traxler, C. "Majority Voting and the Welfare Implications of Tax Avoidance." Journal of Public Economics 96(1-2), 2012, 1-9. 